REVISTA DE DERECHO UNED, NÚM. 14, 2014

\title{
ARTE Y DERECHOS HUMANOS
}

\author{
ART AND HUMAN RIGHTS
}

\section{Manuel VÁzouez Egea}

Investigador-Doctorando de la Facultad de Derecho (UNED). Especialista en derechos humanos y máster en derechos fundamentales. Profesor de música

Resumen: El pretendido encuentro del ser humano con la esencia, o verdad objetiva, ha hecho posible la superación de muy diferentes tipos de obstáculos. Sin embargo, en su anhelo por alcanzar este objetivo, el individuo parece haberse centrado prioritariamente en una clase de conceptualización que tiende a distanciar el término del sentimiento, la teoría de la vida. La divergencia entre palabra y acto puede conducirnos a ciertos automatismos en los que nuestra existencia acabe por no dar cuenta de nuestros pensamientos y en donde el concepto, poco a poco, se vaya desentendiendo de nuestra sensibilidad. En este sentido, al tratar de asignar una definición concreta a la expresión «derechos humanos» se suele obviar, además de los límites de la palabra, la importancia de la sensación y la necesidad de que nuestro «cuerpo» sea partícipe del conocimiento, aspectos estos que el arte sí prioriza. Por ello, la vinculación de la teoría de los derechos humanos con el arte tiene un profundo fundamento, el cual intentaremos demostrar en este artículo. Ambas disciplinas, además de retroalimentarse la una a la otra, vistas en conjunto nos pueden ayudar a alcanzar un mayor y mejor sentido de la humanidad.

Abstract: In the long journey of trying to encounter his essences a human being succeeded in overcoming a multitude of obstacles. Nonetheless, in the process of this quest, an individual seemed to have concentrated excessively on purely theoretical conceptualization prioritizing the concept over sentiment. The divergence between word 
and action could lead us to recite routinely various notions without activity applying then to our daily existence, creating more and more widening gap between concept and sensibility. Therefore, in the process of assigning a concrete significance to the concept of human rights we tempt to overlook the importance of the sensation that this notion evokes. This sensation goes beyond the mere meaning of the words involving our entire being on the emotional level. Throughout, the human history art has been the best vehicle for prioritizing this emotional involvement. There is a profound and intrinsic connection between art and the notion of human rights. In this article, the author will demonstrated this connection. Both disciplines, art and theory of human rights, have served as inspiration for one and other, interpreting in conjoined manner could give us a more profound sense of humanity.

Palabras clave: Arte; derechos humanos; lenguaje; concepto; sentimiento.

Keywords: Art; human rights; language; concept; sentiment.

Sumario: I. Introducción; II. Posibilidades de la palabra; III. Lenguaje y derechos humanos: limitaciones conceptuales y jurídicas; IV. De la desvinculación entre teoría y práctica. Por una lógica artística; V. Arte y derechos humanos: una relación sugerida.

Recepción original: 24/02/2014

Aceptación original: 26/03/2014

\section{INTRODUCCIÓN}

Ante una realidad básicamente desconocida por el ser humano y que es constantemente adaptada e interpretada en interés de la propia supervivencia, resulta sobrecogedora la cándida ilusión que, en ocasiones, mueve al individuo en su lucha por intentar hallar la razón objetiva que determina la esencia de las cosas. Semejante fe en nuestras capacidades, la cual llega a contemplar la posibilidad de trascender nuestras propias limitaciones, podría ser vista por muchos como un acto banal, ocioso o de dulce ingenuidad, pero también podría considerarse un claro ejemplo de osada prepotencia. En todo caso, ante semejante búsqueda son muchos los individuos que a lo largo de la historia han percibido dicha lucha como parte integrante de algún tipo de fin inscrito en nuestro ser, una necesidad que muchos intuyen y que algunos ven susceptible de ser materializada. En verdad, el motor primario que impulsa tan titánica labor podría explicarse de muy 
distintas formas pero, con gran cautela, desde estas líneas se va a apostar por una razón que, a pesar de todas las dificultades, pelea por tomar el mando al respecto, consciente o inconscientemente, y que parece tener mucho que ver con un especial talento humano para sentir y vislumbrar la belleza más allá de la materia, así como con la consecuente necesidad de aprehenderla para que la misma modele sustancialmente nuestras propias vidas.

A lo largo de su historia, el ser humano ha generado, desarrollado y perfeccionado numerosas vías cognoscitivas con la intención de acercarse lo máximo posible al fundamento de la realidad. En este sentido, creemos que tras los mayores éxitos que puedan derivarse de este movimiento palpita un presentimiento de pura belleza que permanece intacto a lo largo del tiempo y que, precisamente por ello, conecta todo tipo de generaciones y formas de vida. Este camino que marca el devenir del sujeto se inicia por y desde el misterio, haciendo del individuo no sólo un superviviente, sino también un artista con ansias de atrapar, aunque sea fugazmente, dicho presentimiento mientras dibuja los contornos de lo desconocido, de lo inmaterial, a través de un sutil sentido estético que le permita confirmar una intuición primaria.

No es de extrañar que, ante un reto semejante, el sujeto recurriese con prontitud al arte, aún en su sentido más primigenio, en sus iniciáticos flirteos con los enigmas más opacos e intrigantes de nuestra existencia, enigmas que poco a poco pasarían a ser conceptualizados con la intención de poder ejercer control sobre los mismos y, de este modo, eliminar los miedos que la confrontación con el misterio pudiese generar. Es así que, remontándonos a los orígenes del fenómeno artístico podemos experimentar la necesidad, ya humana, de un vital aunque temeroso encuentro con la razón a la que el mundo se ve supeditada, un intento por apresar aquello que parece querer escapar de nuestras manos, de personificar algo que se intuye inmaterial. Intento tan válido y provechoso como aquel que podamos llevar a cabo en la actualidad, pero en ausencia de palabra o, quizás, gracias a tal ausencia. Pues si soñamos con un orden universal, un orden que marca el ritmo de los distintos aconteceres, dentro de este gran concierto en el que vivimos quiso ser dispuesto primero, por algún concreto motivo, el sonido, la danza y el dibujo antes que la palabra.

$\mathrm{Y}$ es que, siendo cierto que el fenómeno artístico le debe mucho a la palabra, a veces olvidamos todo lo que la palabra le debe al arte. Eludiendo esta circunstancia, nos arriesgamos a alterar el orden primario dispuesto en ese gran concierto cósmico con el que fantasea- 
mos, desembocando así en una paradoja poco ilusionante pues, si bien nuestros ancestros tenían arte pero no tenían palabra, puede que nosotros (que también somos nuestros ancestros y que también aún estamos por llegar) acabemos con palabras vacías de arte, con conceptos carentes de vida.

En este intento por precisar y limitar lo incorpóreo, por definir y atrapar lo intangible, la palabra, como venimos diciendo, ha ido ganando con el tiempo un justificado protagonismo, derivando rápidamente en conceptos que, a su vez, quedaban circunscritos a teorías cada vez más complejas. Una prosa relevante que, sin embargo, iba pagando un alto precio: eliminar cualquier esbozo de poesía, suprimir cualquier atisbo de arte, quebrar la sensibilidad. Pero, descartado este talento, ¿en qué condiciones determinaremos los vínculos que ligan, o han de ligar, la experiencia vital del individuo con una hipotética razón fundamental?

La teoría de los derechos humanos se viene postulando firmemente, sobre todo desde los últimos tres siglos, como un socorrido y recurrente sistema de clarificación de dichos vínculos. Como no podía ser de otra manera, el mismo no deja de ser un conjunto de reflexiones que, al igual que cualquier otro sistema, incluido el más abstracto, parte de la sensación. Tan sólo a posteriori dicha vivencia se intenta comprender o, mejor dicho, conceptualizar. Pero tras este proceso, si es que el mismo goza de algún tipo de éxito, es fundamental que la teoría sea devuelta a la práctica, que el aprendizaje vuelva al punto del cual partió y en donde, de una forma muy primaria, fue captado por primera vez, esto es, que retorne al cuerpo. Semejante objetivo, a pesar de su aparente sencillez, puede llegar a convertirse en uno de los mayores desafíos de nuestras vidas y, en lo tocante a los derechos humanos, ha de ser un propósito prioritario. Por ello, si aceptamos el reto resultará esencial que nuestro cuerpo no quede atrás durante el trayecto, es decir, que nuestra sensibilidad no vaya a la zaga y, si es posible, se vea potenciada. Pues si la teoría elude este fin, disociando con ello intelecto y sensibilidad, es muy probable que la misma discurra por un camino equivocado, lo que terminará afectando no sólo a la idea, sino también a su generosa y desinteresada expansión.

La conceptualización de ciertos valores y principios en torno a una serie de términos a relacionar con la expresión «derechos humanos» resulta ser, en bastantes ocasiones, un proyecto que roza los límites de la razón práctica y la lógica. Sin embargo la teoría, siempre a la caza del éxito, ha tendido a aferrarse en los últimos tiempos a una especie de materialismo discursivo que, eliminando ya no única- 
mente la subjetividad de "nuestra» palabra, sino también la subjetividad de «nuestra» realidad, ha reconducido a un prototipo de lingüística universal toda concepción de la esencia del mundo y, por tanto, del individuo, circunstancia que ha terminado por afectar a la teoría de los derechos humanos.

Sin lugar a dudas, el hecho de no reconocer como válido el materialismo no restringe en absoluto la admiración que podamos apreciar por la palabra. El problema radica en la sutil, constante e inconsciente equiparación entre palabra y materia, problema que se agrava notoriamente si la palabra no tiene asignado un referente concreto y que, en algún punto, al tratar de afirmar a través de esta relación que en la realidad todo es materia, termina por proclamar que toda la materia puede ser nombrada, por lo que también todo es palabra. De esta forma, los límites de la conceptualización tienden a ser soslayados cayendo, paradójicamente, en un curioso coqueteo con un idealismo que, al tratar de ser negado, es susceptible de desembocar, en el peor de los casos, en algún tipo de fanatismo pero que más solapadamente, y dado su forzamiento, termina provocando una teoría distanciada de la vida, una palabra alejada del acto.

A esta dificultad han de sobreponerse también los derechos humanos, pues los términos o expresiones con los que se pretenden dibujar los contornos de este particular tipo de derechos han demostrado ser, a pesar de avances y retrocesos, generalmente insuficientes. Y lo son porque los mismos, al no gozar de un referente manifiesto y evidente, resultan necesariamente continentes incapaces de abarcar contenidos tan extensos. Tratar de atrapar algo que, en esencia, está más allá de la forma, nos obliga a aguzar una sensibilidad de por sí ya muy limitada, y no sólo respecto a la captación de este contenido, sino también respecto a su posible, aunque restringida, materialización. En este sentido, el abrumador fondo de los derechos humanos sólo podrá ser vislumbrado a través de algo que asombre, al menos, en igual medida a lo más recóndito de nuestro ser.

La palabra, aun considerando todas sus virtudes, no es capaz por sí sola de reflejar este sobrecogedor contenido. Por esta razón, si lo que queremos es ir más allá de sus posibilidades idiomáticas, entonces deberemos cualificar conjuntamente otras vías de conocimiento que potencien nuestros sentidos y nuestra percepción. Todo ello requerirá de nosotros un importante desarrollo de nuestro talento creativo, lo que supondrá un sincero y entregado esfuerzo. Aún así, se trata de una posibilidad con la que todos contamos a pesar de que, por desgracia, muchas veces insistamos obstinadamente en desterrar- 
la de nuestras vidas, cuando no desaprovechar. Poder exprimir esta oportunidad, además de ser un don que nuestra naturaleza nos brinda con el fin de concretar aquello que somos y encaminarnos a aquello que podemos ser, exige un posicionamiento ante la vida particularmente artístico. Desde el mismo, bucearemos en una realidad que nos permita obtener respuestas que no somos capaces de hallar a través de la lógica mundana de nuestra propia existencia pero que, y esto es relevante, si han de ser susceptibles de poder aplicarse suficientemente a ella.

Sin embargo, podría objetarse al respecto lo siguiente: si tanto la palabra como el discurso argumentativo fundamentado en ella, dadas sus limitaciones y su subjetividad, constituyen una posibilidad muy limitada pues no nos aproximan lo bastante a una verdad objetiva, o «esencia», sobre la que fundamentar una realidad como la que tratamos de evocar a través de la expresión "derechos humanos», lo cierto es que el arte y la consecuente perspectiva artística, a priori, deberían partir de las mismas trabas en relación a este tipo de conocimiento. Si esto es así, ¿cómo no pensar del mismo modo en las limitaciones del arte y en la subjetividad implícita al mismo? Efectivamente el arte, como fenómeno comunicativo a la par que humano, es subjetivo y limitado, pero la cuestión primordial en este punto recae en la valoración del tipo de diálogo que nos permite establecer con el mundo y en las particularidades que nos aporta. Un diálogo sumamente trascendental que, al ser entablado a partir de sensaciones muy primarias, puede llegar a poner en contacto muy distintas subjetividades a lo largo del tiempo y del espacio con una intensidad inusitada y en torno a un mismo fin.

D. Antonio Machado y Álvarez, «Demófilo», padre del gran poeta sevillano que tan magistralmente cantó a Castilla y a sus campos, alentaba con gran sabiduría a encontrar respuestas a determinadas preguntas de la siguiente manera: "¿Queréis conocer la historia de un pueblo? Ved sus romances. ¿Aspiráis a saber de lo que es capaz? Estudiad sus cantares» ${ }^{1}$. Y es que el arte esconde un acercamiento a un tipo de conocimiento que no sólo es estético o que, incluso siendo esencialmente estético, nos sorprende constantemente en su aproximación al trasfondo de la vida. Es por esto por lo que recordamos a "Demófilo», por la inspiración que hay en su propuesta y porque, haciendo uso de ella, nos atrevemos a exclamar: «¿Queréis conocer la

${ }^{1}$ GRAnde, Félix, «Memoria del flamenco», Barcelona, Galaxia Gutenberg, 2001, pág. 362 . 
esencia del hombre? ¿Aspiráis a saber cuál es su destino? Ved y estudiad su arte».

Pues la esencia se conecta con el arte, tal y como acabamos de decir, gracias al carácter primario de la sensación. Sólo tras ella puede llegar a producirse el milagro de una emoción que, con tiempo y solera, deriva en sentimiento. A lo largo de este proceso, la palabra surge luchando por conectar todas estas alteraciones para darlas sentido no sólo a los propios ojos, sino también a los ojos de los demás. Pero, curiosamente, en determinadas ocasiones la palabra consigue evaporar esta sensación primaria, patrimonio común que cada individuo ha de llegar a explicarse desde la independencia, la diversidad y la libertad, distanciándonos con ello de la unidad trascendental. Este impacto de la sensación que se esconde tras la unidad tiene mucho que ver con el abrumador fondo de la esencia y de los derechos humanos al que hacíamos referencia en anteriores líneas, un impacto pretendido eternamente por el arte y que cobró especial relevancia en el Renacimiento gracias al gran desarrollo de la composición, es decir, de la culminación del sentido de lo homogéneo desde lo heterogéneo.

Cuanto más difuminada esté la sensación que debería acompañar a la palabra, más lejos se situará esta última de la esencia. Pues una cosa es saber, y otra muy distinta es sentir lo que se sabe. La palabra sentida es palabra vivida, experiencia existencial, "palabra en el tiempo, es decir, participación de toda el alma en lo que se está diciendo»². Una especial forma de comunicación, artística forma, capaz de conducirnos «a esa hermosa memoria que consiste en caer en la cuenta de que el mundo es común y común es la vida, de que el arte es la personalidad de lo colectivo, la identidad tumultuosa de lo comunitario, la fama de lo anónimo, el sobresalto de lo permanente, la caudalosa e irrepetible palabra que pronuncia la especie humana»3.

Este tipo de comunicación parece querer trascender nuestro intelecto y fundirse con la naturaleza, ir más allá de nuestra propia razón en busca de un instante de conexión con el fundamento universal, aquel que siempre ha estado y estará ahí, «observando» nuestros mayúsculos esfuerzos por recorrer un trayecto imaginado, una ilusión de partida y de meta. Verdad al margen del tiempo y el espacio pero que, por alguna extraña razón, insiste en hacerse presente. Misterio de lo innombrable. Sueño de un diálogo despojado de formas y comprendi-

\footnotetext{
${ }^{2}$ Calderón de la Barca, Pedro, «La vida es sueño», Madrid, Cátedra Letras Hispánicas, 1991, pág. 56.

${ }^{3}$ Grande, Félix, óp. cit., pág. 364.
} 
do desde el corazón, pues «las más hondas palabras del sabio nos enseñan, lo que el silbar del viento cuando sopla, o el sonar de las aguas cuando ruedan ${ }^{4}$.

Sin lugar a dudas, la experiencia del ser humano va mucho más allá de su experiencia lingüística, al igual que su experiencia vital va mucho más allá del aquí y el ahora. Es por esto que si, tal y como Albert Einstein afirmó, «ningún problema puede ser resuelto en el mismo nivel de conciencia en el que se ha creado", entonces será necesario algún tipo de mecanismo que nos ayude a vincular preguntas y respuestas a través de los muy distintos planos existenciales posibles o que, al menos, aliente esta especial vinculación. Durante muchos siglos, el arte ha estado al servicio de este objetivo y, muy probablemente, es el único fenómeno que ha sido capaz, incluso a día de hoy, de poder materializarlo en alguna medida 5 . Por esta razón, y aprovechando el hecho de que los derechos humanos son un campo pluridisciplinar que trasciende distintas realidades (de ahí su constante conexión con la esencia), es por lo que consideramos que algunos de los problemas más relevantes que suscitan sus distintos tipos de conceptualización no pueden ser planteados, exclusivamente, desde una perspectiva intelectual que se abandona al ámbito idiomático y al método discursivo común. Es más, estas dificultades, por muy paradójico que pueda sonar dada la propia terminología usada ("derechos» humanos), llegan a escapar muy fácilmente al ámbito jurídico.

Ciertamente la palabra, en todo este proceso, seguirá ocupando un lugar privilegiado, siempre y cuando no perezca, pues nos ayuda en nuestro aprendizaje, facilita la comprensión y expansiona nuestro ser. Pero convendría no hacer de su uso un fin en sí mismo. La palabra es altamente dependiente de muchas otras circunstancias humanas que se vienen poniendo en juego desde mucho antes de su aparición. La conceptualización debería acercarnos a todo este saber previo que el individuo visiona como fin, pero si nuestra sensibilidad no evoluciona al ritmo que se desarrolla nuestra lingüística al concepto, cada vez más intelectualizado, le será difícil ver la luz y correrá el riesgo de quedar soterrado por la teoría, de ser deslumbrado y apabullado por la simple forma. De este modo, el concepto será por siempre idea, pero nunca vida.

${ }^{4}$ Machado, Antonio, «Soledades. Galerías. Otros poemas», Fragmento de «Renacimiento», Galerías, Madrid, Cátedra Letras Hispánicas, 1988, pág. 210.

${ }^{5}$ Dejamos al margen las posibilidades que, al respecto, empiezan a apuntar varias ramas científicas, pues sobrepasan absolutamente muchos de los propósitos de este artículo. En todo caso, es curioso observar la especial vinculación que empieza a surgir entre algunas de las mismas y la perspectiva artística. 
La idea se piensa, la vida se siente. Convertir la idea en vida equivaldría a sentir lo que se piensa, en dar «sentido» al concepto. Creemos que el descubrimiento de este sentido, también en el campo de los derechos humanos, es un camino sumamente personal e individual, un trayecto guiado principalmente por el afán de conocerse a uno mismo, una senda ya marcada que siempre está por recorrer pero que, inmersos en ella, poco a poco se va mostrando tal y como es naturalmente.

La individualización de este trayecto nada tiene que ver con una manipulación egoísta del sentido de la vida y, derivado de ella, con una posible vulgarización de los derechos humanos. Si cada uno de nosotros queremos hacer de nuestra capa un sayo y manejar a nuestro antojo la realidad a la que, antes o después, todos nos hemos de ver abocados, semejante actitud nada tendrá que ver con el desarrollo de la sensibilidad individual. Pues precisamente la comunión en la vida (más allá de la comunión en el concepto) es el fin al que nos ha de conducir este particular desarrollo sensitivo.

En opinión de muchos, los riesgos de manipulación en torno a los derechos humanos aumentan cuando se incorporan al debate las emociones. En verdad, esta crítica responde a serios motivos en algunos aspectos pero, al obviar determinadas perspectivas, genera injustamente una muy mala fama en relación a las emociones. La sensibilidad y la pasión, al igual que la palabra, se educan y se conforman y, por esto mismo, son susceptibles de un buen o mal uso. El problema es que, en determinados ámbitos, la palabra está mejor conformada que la emoción.

Creer en la existencia de una verdad oculta tras los derechos humanos nos encamina a reflexionar en torno a la unidad de un fin que ha de ser sentido. Pero el trayecto que conduce al florecimiento de este presentimiento es verdaderamente íntimo. Sólo cuando está sensación se nos revele, estaremos en disposición de alcanzar la unidad universal que el sujeto parece ansiar desde tiempos inmemoriales.

Esta intimidad de la que hablamos tiene mucho que ver con el gran acontecimiento artístico que toda vida es y cuyo boceto vamos realizando a lo largo del tiempo. Un boceto que empezó a esbozarse hace decenas de miles de años y en cuyo núcleo late una específica mirada de cara a un mejor futuro. Por esta razón es por lo que, a lo largo de las siguientes páginas, intentaremos proponer una visión artística de los derechos humanos pero, para ello, deberemos comenzaremos por analizar algunas de las posibilidades que usualmente nos ofrece la palabra, así como su habitual manejo. Desde este punto, trataremos de generar una impresión de infinitud desbordante que 
necesite de nuevos recipientes para poder contralar su enorme caudal, infinitud que, por otro lado, implica muy directamente a estos derechos con la esencia de la vida humana y que esperamos inspire al lector, al igual que a nosotros mismos, a ver y sentir el arte, así como los derechos humanos, desde un particular posicionamiento a manifestar en nuestro día a día.

\section{LAS POSIBILIDADES DE LA PALABRA}

En unos profundos y sentidos versos, cerca ya del final de sus días pero con la madurez propia del sujeto que se va aproximando a este primordial momento, Juan Ramón Jiménez cantó:

"Acaso la mentira, la duda de este mundo

está en la pobre lengua nuestra.

Si sólo nos pudiéramos mirar

como miras tú, dios, y tú, belleza, miras,

como tú, mi amor, miras,

lo sabríamos todo" ${ }^{6}$.

En estas líneas, puede que influido por el sentir calderoniano y con su habitual melancolía, el poeta de Moguer comparte su anhelo, que es el eterno anhelo del ser humano, por dar sentido a todo lo que le rodea, un sentido que tan sólo podría ser desvelado si pudiésemos, en algún momento, llegar a disfrutar de un ansiado encuentro con la esencia de la vida. Sin embargo, Juan Ramón siembra la duda al respecto pues, al igual que Pedro Calderón de la Barca, parece entrever una realidad difusa y engañosa de la cual somos protagonistas, una especie de realidad onírica que transcurre paralela a la gran verdad existencial, de la cual estamos alejados, y en la que si bien la palabra resulta ser una contingencia más que apta para navegar a través de ella, claramente deriva en un medio insuficiente cuando lo que queremos es dar el salto a esa realidad esencial intuida que Juan Ramón Jiménez, muy sutilmente, define desde una particular trinidad: «dios», «belleza» $\mathrm{y}$ «amor».

Sin embargo, quizás resulte curioso a primera vista semejante acto de confesión por parte del poeta en relación a su gran materia

' JimÉNEZ, Juan Ramón, «Lírica de una Atlántida», en «Como tú, mi amor, miras», Barcelona, Galaxia Gutenberg, 1999, pág. 351. 
prima: la palabra. En efecto, se trata de una sorprendente paradoja, una de tantas contradicciones que el ser humano ha de asumir para poder hacer del mundo un lugar lógico en el que vivir. Aún así, en esta aparente discordancia, teñida de cierta crítica, podemos descubrir un sentido más profundo. Teniendo en cuenta su historia, no creemos que Juan Ramón esté invalidando por completo a la palabra pues, ¿cómo un poeta podría hacer esto? Más bien pensamos que simplemente está destacando su papel dentro de una marcada incomprensión humana, la cual se alimenta de infinitos factores, y alertando sobre sus carencias en relación al conocimiento básico o saber que es fundamento de todo cuanto sucede. Pero hay algo más. Si alguien es capaz de intuir, incluso de llegar a comprender el valor de la palabra, ese es el poeta, por lo que no es circunstancial la crítica de Juan Ramón a la misma, herramienta de la que se sirvió a lo largo de toda su vida para poder encontrar la belleza en un mundo sufriente, molde sobre el que forjar la llave que le debería abrir las puertas de la comprensión del universo, así como de su particular rol en el mismo. Pues él, el genuino poeta, huye de ataduras y reparos en el lenguaje en busca de la representación de su mundo privativo ${ }^{7}$, una perspectiva artística en donde la palabra adquiere nuevos significados, pues su uso y su destino difieren considerablemente del manejo que de ella se hace en el idioma comúnmente.

Desde aquí, Juan Ramón se sirve de la palabra criticada para ir directo al sentimiento y abrir una nueva fuente de conocimiento que pasa, fundamentalmente, por nuestro cuerpo. Y es este sentimiento el principal valedor del elevado saber buscado, situado en un plano distinto, un plano que exige de nosotros la desvinculación de aquello que nos oprime para poder abrazar aquello que nos libera. Desde este lugar, la palabra ya no es sólo palabra, es experiencia viva de una realidad inmaterial de la que se nutre la esencia del ser humano.

En buena medida, este ímpetu trascendental tiene mucho que ver con un tipo de misticismo que, en el caso de Juan Ramón, fue desarrollándose poco a poco pero que referido a otros grandes poetas marcó fuertemente su identidad desde muy pronto. Centrándonos en Jiménez, observamos que dicho misticismo encuentra su fundamento en «su capacidad de expresar lo esencial humano, desde pero más allá de las apariencias sensibles y siempre hacia la realidad invisible» ${ }^{8}$. Por

${ }^{7}$ De Martino, P., «Historia Universal del Arte», Vol. 8, Valencia, Mars-Ivar Editores S. L., 1980, pág. 197.

${ }^{8}$ Catálogos temáticos de la biblioteca de Andalucía, «Juan Ramón Jiménez, Catálogos, Título I, Serie II, 017:821.134.2», en obra coordinada por Alfonso Ramos Torres, Andalucía, Consejería de Cultura, 2008, pág. 11. 
esto, no es extraño asistir al triste lamento del que partimos en relación a la palabra, pues este melancólico poeta la llevó al confín de sus posibilidades al exigirla transmutar de ocasional medio pragmático aplicable a una lógica circunstancial, a obra de arte que nos aproxima a un contenido infinito. Pero este lamento, seguro muy sentido en Juan Ramón, es motivo de alegría para todo aquel que se acerca a alguno de sus poemas, pues este enfermizo onubense consiguió más de lo que imaginó. En su pluma, esa criticada palabra se convirtió en vida, llegando su biografía a confundirse «con la historia de sus libros, hasta convertirse en una forma de estar en el mundo, en la que la poesía ocupa el primer plano de todos y de cada uno de los momentos de la existencia del personaje»9.

En relación a este último apunte, resulta importante advertir que la manifestación artística llega a ser un singular acto comunicativo cuando acaece una fusión esencial entre la creación y el creador, de tal forma que al contemplar su obra alcanzamos a escudriñar la propia vida del autor, su propia alma. Producido este hecho, imaginar que artista y obra constituyen dos tipos de personalidades distintas puede devenir en una experiencia penosa y decepcionante ${ }^{10}$. Por ello, cuando estamos en presencia de las grandes obras de todos los tiempos, regalos ofrecidos por el inmenso y aprovechado talento de unos cuantos individuos, lo cierto es que no sólo vemos arte, pues llegamos a ver una auténtica y genuina forma de vida.

Leer a Machado, a Lorca, a San Juan de la Cruz, a Santa Teresa de Jesús, a Pedro Calderón de la Barca o, simplemente, tropezarse con alguna copla lejana y anónima que, de repente, canta nuestro particular presente, implica revivir esta experiencia, pues al igual que el escultor se muestra en sus tallas, el arquitecto en sus construcciones, el pintor en sus lienzos y el músico en los sonidos y en los silencios, estos grandes poetas se nos dieron por entero a través de la palabra. Y esta comunicación puede volverse tan íntima y misteriosa que, en algún momento mágico y aún sin saber concretamente las razones de tan fantástica sensación, terminamos percibiendo la transmisión sincera y directa de un conocimiento eterno que se actualiza en nuestras propias carnes. A esta alturas, la vinculación que se establece es de tal calado que si el artista, por un casual, traiciona contundentemente con su vida su personal obra, es decir, si su obra no encuentra fiel reflejo en su vida, entonces la percepción de su arte quedará seriamente afectada. Aún así, no todo estará perdido. En este momento

\footnotetext{
${ }^{9}$ Ibídem.

${ }^{10}$ ZWEIG, Stefan, «El misterio de la creación artística», Madrid, Ediciones Sequitur, 2010, pág. 20.
} 
(especialmente en este momento, en el derrumbe de la leyenda y del mito), tendremos la posibilidad de experimentar más conscientemente un fenómeno siempre implícito en el arte pues, al admirar cualquier obra con un mínimo de sensibilidad, instantáneamente también nosotros nos convertiremos en artistas en busca de belleza. La obra de arte, en su sentido más pleno, ya no sólo pertenecerá al artista, también nos pertenecerá a nosotros gracias a un fugaz momento en el que todo nuestro ser parece haber visualizado un atisbo de verdad que gozamos con especial entusiasmo. Hemos llegado a intuir un conato de belleza y queremos ir a su encuentro, queremos que esté permanentemente en nosotros, que forme parte de nuestra vida y de nuestro estar en el mundo. Y es así como, con el fin de modelarnos de acuerdo a esa belleza intuida, nos convertimos en artistas.

Esta comunicación que nos emociona, que «nos pone en movimiento» fusionando mundo interno y mundo externo, será más plena cuanto más intensamente estén involucrados en la misma todos nuestros sentidos. Enriquecida la comunicación, es de esperar que el conocimiento adquirido a raíz de todo este movimiento también devenga más completo. Precisamente con este fin, pero dejando a un lado una parte importante de nuestra capacidad sensitiva, poco a poco fueron ganando fuerza, con especial relevancia a partir del siglo XIX, aquellas líneas de pensamiento que centraban y reducían el conocimiento (objetivo) a los aspectos lingüísticos del lenguaje. Al margen de muchos otros talentos y por medio de múltiples argumentos, de repente la palabra pasó a postularse como sustento nuclear de toda experiencia humana. Es más, su capacidad funcional llegó a estar en tal estima que muchos pensadores, con gran ahínco, terminaron por hacer depender nuestro conocimiento de la realidad de nuestros conocimientos lingüísticos.

Esta visión pragmática del lenguaje fue un proceso que se vino preparando, principalmente, desde el racionalismo ilustrado y que desencadenó un marcado logicismo influido por la filosofía analítica del momento. Desde esta perspectiva, se trató de ofrecer una comprensión válida de la realidad en base al descubrimiento de la razón oculta tras el significado de las palabras y las oraciones, así como de los conceptos adjuntos a estas últimas, evitando recurrir a entidades extra-lingüísticas o a una supra-conciencia universal ajena al lenguaje, el cual "pasa a ser un fenómeno de carácter único y fundante» ${ }^{11}$. De esta forma, él y sólo él ordena el mundo posibilitando, condicionando

${ }^{11}$ CORREDOR LANAS, Cristina, "Filosofía del lenguaje. Una aproximación a las teorías del significado del siglo XX», Madrid, Visor, 1999, pág. 23. 
y constituyendo nuestra experiencia y, por esto mismo, el conocimiento objetivo.

Semejante profundización lingüístico-científica en los ámbitos del lenguaje hizo depender una gran parte de sus éxitos de los aspectos más prosaicos de la palabra, dejando con ello a un lado sus aspectos más poéticos, es decir, apartando de su reflexión la importancia del arte. Por si fuera poco, todas estas teorías terminaron cayendo, antes o después, en relevantes contradicciones o llegando a puntos en donde las explicaciones lógicas no podían dar más de sí. De esta manera, la palabra no sólo no había podido explicar el mundo, también había sido tristemente cercenada. Se quisieron obviar los límites de la misma desde un aspecto puramente material, sin tener en cuenta que el sentimiento poético es imprescindible si aspiramos a hacer del concepto vida. ¡Quizás fuese esta la pena que veíamos reflejada en el poema de Juan Ramón Jiménez!

\section{LENGUAJE Y DERECHOS HUMANOS: LIMITACIONES CONCEPTUALES Y JURÍDICAS}

Si bien el surgimiento y desarrollo del lenguaje hablado y escrito son hitos fundamentales en la historia del ser humano, su análisis y vinculación con las posibilidades cognitivas del ser tomará un rumbo muy peculiar a partir de la segunda mitad del siglo XIX, orientación que se mantendrá durante la primera mitad del siguiente siglo. A este respecto, tres serán prioritariamente las líneas de pensamiento que tratarán de cimentar en el lenguaje un posible reconocimiento de la esencia, verdad natural o realidad objetiva ${ }^{12}$, guardando todas ellas sugerentes puntos de conexión con las tres principales teorías del derecho que han pretendido dar fundamento al fenómeno jurídico y, por derivación, a los derechos humanos.

Dentro la moderna filosofía del lenguaje destacamos una primera línea de pensamiento que agrupa a un conjunto de teorías denominadas «intensionalistas». En ellas, lo verdaderamente relevante del acto comunicativo son los estados intencionales de las personas o hablantes, es decir, lo que desean, lo que quieren, lo que pretenden, lo que temen o lo que esperan. De este modo, la comunicación tiene lugar

${ }^{12}$ Estas teorías se agrupan dentro del esquema que señaló el lingüista y filósofo alemán, Karl Bühler, en relación a las distintas posibilidades que nos pueden ofrecer las expresiones lingüísticas: 1) expresar las vivencias del hablante; 2) representar estados de cosas y; 3) establecer relaciones interpersonales con un interlocutor. Ibídem, pág. 42. 
gracias a la transmisión de esos estados intencionales de conciencia a través del lenguaje ${ }^{13}$. Sin embargo, existe al respecto un serio inconveniente pues «lo que se quiere decir» no está en modo alguno determinado por lo que de hecho «se dice», de tal forma que lo fundamental será atender a lo que un sujeto pretende comunicar, más allá de lo que de hecho pueda estar comunicando. En este sentido, las teorías intensionalistas analizan el lenguaje como un mecanismo que puede reflejar exactamente las intenciones de un determinado hablante pero, al situar en un lugar privilegiado dichas intenciones, terminan apelando a un particular tipo de «intuiciones pre-teóricas básicas» para poder explicar cuestiones tan importantes como el carácter público de los significados. Por este motivo, estas teorías acaban por conectarse, en muchas ocasiones, con aquellos paradigmas que apelan a un tipo de conciencia humana universal accesible para todos los sujetos, conciencia donde radica el fundamento de todo conocimiento y que, desde la filosofía del lenguaje, encontrará correlativo argumento en la pretendida conciencia universal lingüística.

Las teorías intensionalistas del lenguaje, sobre todo cuando no consiguen desvincularse plenamente del paradigma mentalista basado en la conciencia universal kantiana, presentan ciertas coincidencias en su propuesta con determinados aspectos del iusnaturalismo y, en concreto, con su particular perspectiva de la teoría de la norma. Efectivamente, al igual que los intencionalistas pretenden acceder al fundamento del lenguaje a través del conocimiento de las intenciones de los hablantes, los iusnaturalistas pretenden acceder al fundamento del derecho a través del conocimiento de la justicia ${ }^{14}$, lo que conlleva ciertos paralelismos entre los dos posicionamientos al hacer depender ambos, en mayor o menor medida, todo conocimiento humano del conocimiento de la naturaleza en su sentido más trascendental, es decir, de una especie de advenimiento de un saber superior que encuentra acomodo en nuestros horizontes racionales.

$\mathrm{Al}$ respecto, el paradigma de la propuesta iusnaturalista es la existencia de un derecho natural universal y previo al cual el derecho positivo se ha de adaptar. Cualquier norma que se aleje de los principios que marca este derecho derivará en norma injusta. Tal consideración exige la existencia de un saber previo y eterno que define lo

${ }^{13}$ Señalamos a este respecto que el sentido de conciencia en estas teorías empieza a distanciarse del sentido de conciencia en Kant, línea de pensamiento la suya que, pese a poder ser considerada en algunos aspectos intensional, tiene importantes diferencias con el rumbo que la misma tomará a partir del siglo XIX.

${ }^{14}$ Boвbio, Norberto, «Teoría General del Derecho», Madrid, Editorial Debate, 1991, págs. 13-51. 
que es correcto e incorrecto, siendo labor del ser humano decodificar este conocimiento superior a través de la razón para, una vez aprehendido, poder manifestarlo y comportarse de acuerdo al mismo. En este sentido, del mismo modo que la perspectiva intensionalista podía conducirnos a una concepción pre-teórica del lenguaje y a un mundo en donde las intenciones son subsumibles en una conciencia universal, siendo la palabra «intencionada» la culminación de todo un proceso intelectual que trata de materializar ese lenguaje pre-existente inscrito en el ser humano, la perspectiva iusnaturalista nos llevaría a una concepción pre-teórica del derecho. Desde este punto de vista, por ejemplo, los derechos humanos formarían parte de un derecho supremo que muchos, precisamente por su carácter pre-teórico, niegan ya que, entre otras cosas, consideran imposible una visión compartida de esa justicia eterna y natural, haciendo inaplicable dicho derecho por su falta de objetividad. Por ello, distintas tendencias han visto con pesimismo la fundamentación de la norma más allá de la ley impresa y positiva del mismo modo que, dentro del ámbito lingüístico, podría verse con ciertas cautelas la fundamentación de la palabra en base a las intenciones del sujeto, lo que supondría correr el riesgo de caer en un lenguaje plenamente subjetivo y con grandes dosis de relativismo, imposibilitando así la comunicación. En definitiva, y por centrar el problema, todo este cúmulo de dificultades podría resumirse en dos cuestiones bastante concisas: 1) ¿sería posible llegar a un acuerdo lingüístico sobre el referente que se adhiere a la palabra «dignidad» si nos atenemos, simplemente, a las intenciones de los hablantes cuando hacen efectivo uso de dicho término?; 2) ¿contamos con un idioma capaz de transmitir literalmente nuestras intenciones cuando apelamos a este valor?

Vistos estos aspectos de la teoría intensionalista, pasamos a desarrollar una segunda línea de pensamiento que se centra en las llamadas teorías semantistas. Para dichas propuestas, cuando relacionamos las expresiones lingüísticas con el mundo que nos rodea lo que hacemos es destacar la función representativa del lenguaje y, más concretamente, la función representativa del significado asociado a una determinada expresión. Desde esta perspectiva, se incidirá en el estudio de las condiciones «de verdad» de los enunciados en su sentido lógico-formal mediante el análisis de sus estructuras, atribuyendo al lenguaje un estatuto de autonomía respecto a las intenciones y representaciones subjetivas de los hablantes. En este sentido, tanto la práctica en el uso del lenguaje (aspecto prioritario para las teorías intersubjetivas que veremos a continuación), como el componente psicológico en la comprensión del significado ocuparán un lugar se- 
cundario frente al sistema de reglas sintácticas y semánticas con el que se construyen las proposiciones. De este modo, el empleo y la comprensión correcta de una expresión no serán resultado de las intenciones o de las convenciones acordadas por los usuarios de una lengua, sino de las propiedades formales y reglas de formación de las propias expresiones. Por ello, para los semantistas la unidad significativa mínima la constituirá el enunciado en lugar de la palabra, pues sólo él puede expresar un estado de cosas en el mundo objetivo compartido por hablante y oyente, representación que se produce gracias a la vinculación que se da entre significado y verdad objetiva ${ }^{15}$. Sin embargo, ligar las condiciones de verdad de un enunciado al conocimiento que hablante y oyente tienen de ella plantea varias dudas pues, ¿son accesibles estas condiciones de verdad para los individuos en términos objetivos? ¿No es acaso el conjunto de reglas sintácticas y semánticas de las proposiciones del lenguaje una convención más, puede que incluso basada en las intenciones de los hablantes?

Semejante perspectiva lingüística, tan vinculada al análisis lógico de las estructuras semánticas en condiciones de verdad o falsedad, encuentra fuertes conexiones con el positivismo y su concepción del derecho ${ }^{16}$. Efectivamente, si bien los semantistas darán una importancia fundamental a la estructuración de las proposiciones para que las mismas puedan reflejar válidamente la realidad, los positivistas, en base a la teoría institucional, propondrán como principio básico la estructuración del derecho y la organización de las instituciones, pues sólo el empleo de unos cauces determinados en la promulgación de las normas será lo que otorgará legitimidad a las mismas. Consecuentemente, la realidad jurídica será, ni más ni menos, aquella que esté reflejada en un cuerpo jurídico correctamente promulgado. Por desgracia, semejante priorización de la estructuración funcional y de la lógica, como bien podemos comprobar en nuestra más reciente historia, aunque necesaria en ciertos aspectos para la supervivencia del individuo, contiene serios inconvenientes y, quizás por esto, en muchos casos ha degenerado en auténticas perversiones intelectuales con graves resultados prácticos.

${ }^{15}$ Dicha vinculación se fundamenta en el siguiente axioma: 1) Si el significado de un enunciado viene dado por el estado de cosas que dicho enunciado figura, reproduce o refleja y; 2) si el enunciado es verdadero cuando el estado de cosas expresado existe, o es el caso, entonces; 3 ) será legítimo afirmar que entendemos lo que significa el enunciado sólo cuando conocemos las condiciones bajo las cuales éste es verdadero. Ver CORREDOR LANAS, CRISTINA, óp. cit., pág. 44.

${ }^{16}$ BobBio, Norberto, óp. cit. 
En verdad, muchas de estas teorías suprimieron el legítimo interés del individuo por indagar en la posible existencia de una realidad, o verdad, superior y objetiva, pasando a centrarse, simplemente, en aquella realidad que supuestamente puede ser conocida y gestionada por el ser humano. A pesar de ello, lo curioso es que, en no pocas ocasiones, las mismas acabaron exigiendo su aceptación como si de una verdad suprema se tratase. Por ejemplo, aunque las teorías semantistas parecen tener en cuenta la existencia de un mundo objetivo capaz de ser interpretado por el lenguaje, lo cierto es que al poner el acento tan vehementemente en el idioma terminan dando por hecho que, mientras la proposición sea lógica y coherente, y se corresponda con aquello que observamos, esa información, y sólo esa, será la autentica realidad. Pero nuestra propia experiencia nos insinúa constantemente que la realidad no es abarcable por el idioma, pues escapa, una y otra vez, a nuestra capacidad lógica y rehúye permanentemente ciertos encorsetamientos lingüísticos. Verdaderamente, hay una realidad más allá de las palabras al igual que, dentro de los derechos humanos, hay una realidad jurídica más allá de un determinado cuerpo legal. Pues el hecho de que un ordenamiento jurídico responda a determinados criterios de validez sustentados por un procedimiento aparentemente legítimo, no implica que dicho ordenamiento se ajuste a ciertos criterios de justicia. Sin duda, es necesario un principio superior. Afirmar que algo es lógica y válidamente derecho no significa que sea sentido y vivido como auténtico derecho.

En definitiva, y para cerrar esta segunda línea de pensamiento, tanto las teorías semantistas como las teorías positivistas parecen querer obviar un tipo de percepción que parece estar inscrita en el ser humano naturalmente. Francamente, muy a menudo sentimos, y lo hacemos muy vívidamente, que la realidad que observamos y definimos es una ínfima parte de la realidad con mayúsculas, incluso quizás un tipo de interpretación de la misma, puede que tergiversada, una realidad que esconde un misterio que nuestro intelecto parece no estar preparado para asumir. Sin lugar a dudas, estas consideraciones también afectan a la realidad que se esconde tras los derechos humanos la cual, como hemos dicho, va mucho más allá de la realidad que puede ser observada y definida. De esta forma, ante tal infinitud tenemos, como mínimo, dos opciones: 1) obviar este tipo de realidad pues, tal y como muchos teóricos asumieron, al no estar el ser humano capacitado para acceder a ella no merece la pena entrar en disquisiciones sobre la misma o; 2) considerar que, aunque dicha realidad no sea «trasladable» por completo a nuestro plano existencial, y teniendo en cuenta que dicha realidad sencillamente «es», de donde se 
deduce su verdad y belleza, es posible establecer ciertas vinculaciones que nos ayuden a dibujar sus contornos y, a la par, nos sirvan de guía para que nuestras vidas puedan armonizar mejor con los mismos.

Finalmente, existe una tercera línea de pensamiento centrada en las teorías intersubjetivas del lenguaje, las cuales estudian fundamentalmente las razones por las que se establecen relaciones interpersonales entre los distintos interlocutores. En ellas se destaca el intento por explicar el significado desde una concepción pragmática, es decir, en términos del uso que los hablantes hacen del lenguaje. De esta forma, lo que genera el vínculo entre la actividad y el habla es la concordancia regular en nuestro interior de una forma de vida intersubjetivamente compartida, una especie de pre-comprensión de una práctica común regulada por usos e instituciones comunes. Este planteamiento enfatiza el entretejimiento del lenguaje como una praxis interactiva que se plasma en una forma de vida. Con ello, la relación entre hablante y oyente será el reflejo de prácticas previamente establecidas en común atendiendo a la multiplicidad de funciones del lenguaje.

Dicha multiplicidad fue afirmada por Ludwig Wittgenstein quien, tras defender en un primer momento la semántica de condiciones de verdad, descubrirá el carácter de acción de las expresiones lingüísticas y la pluralidad de usos del lenguaje. En parecido posicionamiento, J. L. Austin vino a destacar la "fuerza ilocutiva del lenguaje», en donde la emisión de un acto de habla entraña, al mismo tiempo, la comunicación del tipo de acción que el hablante está llevando a cabo. Teniendo en cuenta esto, el entendimiento se logrará gracias al contenido comunicado y al modo de la comunicación, siempre que exista la posibilidad de vincular dicho contenido proposicional comunicado al compromiso particular del propio hablante. De esta forma, el lenguaje prevalecerá sobre las intenciones de los hablantes, pues las personas tienen estados intencionales precisamente porque la comunicación y la comprensión existen previamente a ellos y a las reglas sintácticas y semánticas del idioma. Sin embargo, el principal problema para las teorías intersubjetivas, tal y como veremos a continuación, surgirá cuando traten de argumentar la efectiva concordancia práctica entre el contenido que se comunica y la forma, o modo de hacer, de los distintos sujetos a la hora de transmitir ese contenido.

En este sentido, si se pretende fundamentar la realidad a través de una particular perspectiva lingüística que, a su vez, constituye el mundo, entonces también será necesario hacer coincidir las consecuencias de dicha perspectiva pues, de lo contrario, ¿qué nos impediría reparar en una pluralidad de mundos lingüísticos y, con ello, una 
pluralidad de realidades dispares? La única respuesta al respecto nos obligaría a explicar el lenguaje como fenómeno universal, circunstancia que fue, de hecho, lo que trató de hacerse al trasladar la unidad de conocimiento del sujeto trascendental de Kant, o conciencia, a «un proceso de comunicación lingüística que tiende a unificar lo plural de las distintas perspectivas sobre el mundo ${ }^{17}$, proceso que será desarrollado por Ch. S. Peirce.

En su teoría, Peirce situará la base del conocimiento intersubjetivamente válido en la función simbólica del lenguaje, es decir, aquella que remite a conceptos y en la que, precisamente por ello, su referencia no está clara ni es unitaria. Esta función ha de garantizar la comunicación intersubjetiva, por lo que será necesario un juicio de la percepción que interprete los símbolos conceptuales del lenguaje, interpretación que será irremediablemente dependiente de la tradición y costumbre. Es así que, desde esta perspectiva, la verdad como validez intersubjetiva del conocimiento «solamente podría quedar definitivamente asegurada por medio de un proceso de reinterpretación y formación de consenso, en principio ilimitado», de tal forma que «el proceso del conocimiento es discursivo a todos los niveles» ${ }^{18}$. Pero, ¿quién será el encargado de interpretar y reinterpretar este procedimiento? Peirce pondrá solución a esta diatriba postulando la necesidad de una comunidad indefinida de investigadores o intérpretes, que serán los que sienten las bases del proceso.

Sin embargo, siendo el fundamento de la teoría de Peirce sustancialmente pragmático, su propuesta termina por acercarnos, en mayor o menor medida, a un determinado tipo de trascendentalismo por dos razones básicas. En primer lugar, al no ser posible encontrar con cierta solvencia un límite válido a dicho proceso, el mismo degenera rápidamente en un argumento ad infinitum. Y en segundo lugar, al no ser susceptible de comprobación empírica (pues nunca podremos juntar a esa "comunidad indefinida de intérpretes»), entonces será necesario un presupuesto contra-fáctico desde el cual partir a la hora de elaborar una argumentación discursiva eficiente y, en este sentido, ¿cuál será este presupuesto? Por lo demás, deberemos también tener claro quién o qué otorgará legitimidad a esa comunidad de investigadores o intérpretes.

G. H. Mead, con la intención de encontrar dicha legitimidad, involucrará a toda la sociedad en la constitución de los sentidos lingüísticos. Para Mead la sociedad interfiere necesariamente en el «yo», y la

\footnotetext{
${ }^{17}$ Corredor Lanas, Cristina, óp. cit., págs. 25-26.

${ }^{18}$ Ibídem, págs. 28-29.
} 
conciencia que exteriorizamos está, del mismo modo, inevitablemente ligada a la intersubjetividad lingüísticamente mediada ${ }^{19}$. De esta forma, «los propios significados, o sentidos lingüísticos, se aprehenden reflexivamente sólo a partir de procesos de interacción personales, en los cuales aprendemos a adoptar la perspectiva del otro o de los otros», por lo que los sentidos lingüísticos no son algo dado de antemano que es aprehendido reflexivamente en nuestro interior, ni tampoco originario, pues «lo verdaderamente originario [...] no es una conciencia de sí autónoma, sino la conciencia que surge de las expectativas y juicios valorativos que mis interlocutores tienen con respecto a mí» ${ }^{20}$.

Pero para poder adoptar la perspectiva del otro, Mead considerará necesaria una reciprocidad de expectativas a la que sólo se puede acceder por medio de la comunicación interpersonal, la cual institucionaliza el lenguaje a través del proceso de interpretación mutua, y en donde «los gestos así internalizados son símbolos significantes porque tienen las mismas significaciones para todos los miembros de la sociedad o grupo social dado ${ }^{21}$. Sin embargo, el problema del relativismo lingüístico sigue sin resolverse ya que, en principio, la interacción humana no tiene por qué revestir una forma única y universal.

Y esta es, precisamente, la gran dificultad, pues todas estas teorías universalistas necesitan "no sólo garantizar la identidad intersubjetiva del significado (y) la posibilidad de procesos de entendimiento no predeterminados por la constitución histórica del lenguaje y los rasgos culturales particulares (sino también) que todos los procesos de constitución de estructuras de sentido tienen lugar sobre una base común, que se articulan de acuerdo con estructuras formales que se repiten en todas las comunidades lingüísticas y que, por tanto, constituirán eventualmente la condición de posibilidad de procesos interculturales de entendimiento y diálogo ${ }^{22}$. Por todo ello, y teniendo en cuenta los beneficios que se hayan podido obtener de semejantes propuestas, es importante observar que, antes o después, los distintos paradigmas terminan llegando a un trascendentalismo que escapa al pragmatismo más estricto.

Aún así, este pragmatismo intersubjetivo lingüístico tiene también, como no podía ser de otra manera, un referente jurídico oportuno estructurado, en este caso, alrededor de las teorías realistas del derecho y, más en concreto, a su particular concepción de la teoría relacional.

\footnotetext{
${ }^{19}$ Ibídem, pág. 31 .

${ }^{20}$ Ibídem.

${ }^{21}$ Ibidem, págs. 32-33.

22 Ibídem, pág. 35.
} 
Para esta escuela lo característico del derecho será el conjunto de relaciones que se da entre los distintos sujetos, de tal modo que si uno tiene el poder de ejecutar una acción otro tendrá, como mínimo, el deber de no impedir que el primero pueda realizar dicha acción ${ }^{23}$. De esta forma, al poner el punto de atención en el seguimiento de la norma por parte de los sujetos, el realismo jurídico verá en la eficacia el elemento definitorio respecto a lo que es o no es derecho.

Como vemos, ya sea desde el lenguaje, ya sea desde el propio derecho, lo relevante en ambos casos será descifrar una pauta general eficiente en base al comportamiento humano. De ello se deduce que si, dado el caso, lo que queremos es descifrar el sentido y contenido lingüístico de la expresión «derechos humanos», entonces deberemos analizar la convención social que ha dotado de significado a dicho término en base a los usos del mismo y a la práctica cotidiana. Dicho análisis será el único que, según las pautas del inter-subjetivismo, nos pueda ofrecer garantías respecto a qué son los derechos humanos. Del mismo modo, si lo que queremos es hallar el contenido jurídico de los derechos humanos, entonces deberemos, según las pautas del realismo, atender a la eficacia de las normas referidas a este tipo de derechos.

Al priorizar la convención social en función de su grado de aceptación el realismo jurídico, al igual que las teorías intersubjetivas del lenguaje, bordea fuertemente el relativismo. Es decir, al eliminar como criterios de referencia la justicia y la validez, la concepción del derecho se ve expuesta al albur de las circunstancias y la verdad objetiva tiene como único sustento el propio acuerdo intersubjetivo. Por lo demás, hay que considerar que la eficacia de una convención puede deberse a muy diversas razones, y no todas ellas suficientemente convincentes o justificables. Todo ello podría derivar, por ejemplo, en un sometimiento del contenido de los derechos humanos a las tendencias y preferencias del momento las cuales, a su vez, pueden ser sumamente volubles y partidistas. Los usos y las convenciones varían, los acuerdos van y vienen y, por ello, fundamentar una cuestión esencial en base a circunstanciales pautas sociales puede ser una solución momentánea pero, a la larga, se antoja insuficiente por lo que al acuerdo, ya necesario de por sí, habrá de exigírsele algún tipo de referente más.

En verdad, tanto en el marco de la filosofía del lenguaje, como en el marco de la filosofía del derecho, el problema que acabamos de reseñar es uno de los más recurrentes en todas sus teorías: la necesi-

${ }^{23}$ Boввіо, Norberto, óp. cit. 
dad de hallar un referente superior que termine de validarlas. El encuentro con dicho referente no deja de ser un enigma al que constantemente tratamos de aproximarnos de muy distintas formas. Semejante misterio puede incitarnos, en ocasiones, a trascender la lógica imperante del mundo que conocemos para así poder romper esquemas habituales y reincidentes en nuestro pensar y en nuestro sentir. Enfrentarse a este estimulo demandará valentía y creatividad, pues la finalidad es transformar las intuiciones inmateriales en una realidad tangible de la que nuestra especial sensibilidad será, si no el único, si al menos su mejor testigo.

Los derechos humanos son, con sus propias características, un particular movimiento del individuo en busca de ese referente superior del que venimos hablando. Al respecto, el problema lingüístico adjunto a la expresión «derechos humanos» es un ejemplo paradigmático de todas las dificultades que, desde siempre, suscita el pretendido encuentro del sujeto con la esencia. Una dificultad que, por cierto, compromete igualmente al ámbito jurídico, viéndose seriamente afectado por ello. Sin lugar a dudas, no resultará fácil vislumbrar un éxito pleno en esta compleja empresa pero, a la vista del tipo de conceptualizaciones que se vienen priorizando en este campo, hacer recaer en la palabra todo el peso de esta labor puede ser una equivocación subsanable.

La mayor demostración de las implicaciones jurídicas que pueden derivarse del problema lingüístico en relación a los derechos humanos es, sin duda, el notable contenido polisémico de esta expresión. Ante esta situación, el término en cuestión acaba por presentar una enorme vaguedad conceptual, lo que propicia serias confusiones además de dificultar su comprensión y arraigo. Norberto Bobbio fue, en este sentido, sumamente crítico respecto a la ambigüedad del concepto "derechos humanos", rechazando la posibilidad de uso de los tres tipos de definiciones que habitualmente habían pretendido explicar este particular fenómeno jurídico, es decir, las definiciones tautológicas, las definiciones formales y las definiciones teleológicas ${ }^{24}$. Al respecto, todas ellas acaban siendo una "fórmula genérica que oculta, sin resolver, la diferencia de pareceres ${ }^{25}$, además de terminar apelando a

${ }^{24}$ Pérez Luño, Antonio Enrique, «Derechos Humanos, Estado de Derecho y Constitución», Madrid, Tecnos, 2005, pág. 27.

${ }^{25}$ Boввіо, Norberto, "L'illusion du fondement absolu», Simposio sobre el fundamento de los derechos del hombre del Institut International de Philosophie, celebrado en L'Aquila, del 14 al 19 de septiembre de 1964, recogido en BoBBio, Norberto, «Sobre el fundamento de los derechos del hombre» en El problema de la guerra y las vías de la paz, Barcelona, Editorial Gedisa, 1982, págs. 117-128. 
valores últimos, los cuales «son interpretables de modo diverso según la ideología del intérprete» ${ }^{26}$, lo que impide la obtención de una definición legal.

Finalmente fue consensuado por una parte mayoritaria de la doctrina el uso de un tipo de definición nominal, concretamente la definición explicativa, gracias a la cual podrían esclarecerse, supuestamente, los conceptos clave en una cultura determinada en relación a una concreta expresión o realidad (en este caso, los derechos humanos), lo que nos debería llevar a obtener una definición adecuada de la mis$\mathrm{ma}^{27}$. Sin embargo, lo cierto es que tanto a nivel teórico como, sobre todo, a nivel práctico, el uso de este tipo de definición no ha eliminado problemas recurrentes que enlazan con ciertas críticas aplicables a las teorías intersubjetivas del significado. Del mismo modo, los consensos semánticos siguen mostrando grandes carencias a la hora de tratar de abarcar determinados contenidos conceptuales y de conseguir descifrar una realidad que, dada su esencialidad, supera con creces las posibilidades de dos simples ámbitos del conocimiento, el lenguaje y el derecho, por muy importantes que los mismos sean.

Si los derechos humanos generan grandes divergencias y numerosos conflictos es porque, ante todo, muestran de forma muy clarividente una eterna inmadurez del ser humano que, como si de un bebé se tratase, ha de afrontar en pañales su propio y particular misterio. Sin embargo, tras esta inmadurez se esconden infinitas posibilidades, una fuerza vital arrolladora que, en algún privilegiado instante, parece ser iluminada por un especial ápice de conocimiento (de difícil articulación lingüística) que nos acerca a un tipo de realidad, verdaderamente ideal, que tratamos de materializar.

Los derechos humanos podrían ser muy bien un paradigma respecto a esta vibrante iluminación, un presentimiento basado en una intuición sobre una realidad de paz y bien en un mundo donde, irremediablemente, la disputa y el mal también entran en juego. Pero al ser humano, ansioso por enfrentarse a sus limitaciones, no le basta con el presentimiento, pues necesita hacer del mismo sentimiento. Ante esto, la labor de legisladores y magistrados, por muy valiosa que

${ }^{26}$ Ibídem.

${ }^{27}$ PÉrez Luño, Antonio Enrique, «Teoría del Derecho. Una concepción de la experiencia jurídica», Madrid, Tecnos, 2008, págs. 34-36. En todo caso, lo cierto es que la propuesta que aboga por el uso de definiciones explicativas no ha eliminado un tipo de descripción que conjuga cierto formalismo lingüístico con un sutil, y a veces manifiesto, idealismo iusnaturalista, ya sea consciente o inconsciente, y que termina por acercarnos, en mayor o menor medida, a un tipo de visión intensionalista del término "derechos humanos». 
pueda resultar, tiene ciertos acotamientos, como también los tiene el manejo de una aséptica perspectiva lingüística. La ley, al igual que la palabra, es incapaz de determinar por sí misma la realidad que se oculta tras los derechos humanos y, aunque pretendiese hacerlo haciendo uso de su poder, ¿qué tipo de realidad advendría a raíz de ello? ¿Acaso una realidad impuesta a la mayoría pero, en el mejor de los casos, es decir, dando por hecho que la realidad advenida es «objetivamente» buena, sentida -vivida- por una minoría? Puede que semejante solución funcionase a corto plazo pero, ¿y a largo plazo? ¿Podría quedar el sentido de los derechos humanos verdaderamente inscrito en nuestra personalidad a través de estos mecanismos? Es más, ¿qué tipo de derechos humanos quedarían inscritos?

En relación a ello, el más sugerente misterio de los derechos humanos, o al menos el más obvio desde un punto de vista conceptual y, derivado de ello, desde un punto de vista jurídico, es el siguiente: ¿qué referente les asignamos? A primera vista, el «acuerdo implícito ${ }^{28} \mathrm{pa}-$ rece ser en la actualidad el más habitual tipo de mecanismo decisor, siendo así el sustento principal que ha de otorgar valía suficiente al referente. Sin lugar a dudas, no podemos negar categóricamente la funcionalidad que haya podido alcanzar este tipo de herramienta decisora en la organización de nuestras modernas sociedades, así como su utilidad en relación a la toma de ciertas decisiones sobre cuestiones que escapan a nuestro ámbito de conocimiento y que, aún así, nos afectan. Sin embargo, si por algo ha luchado el individuo a lo largo del tiempo, por mucho que a veces pueda parecer todo lo contrario, es por ser, en todo lo que pueda, gestor de su propia vida y de sus propias decisiones.

En este sentido es el propio sujeto, a nivel particular, el que ha de proyectar gran parte de la luz que debe recaer sobre el enigma relacionado con el referente básico de los derechos humanos pues, en definitiva, tal referente ha de ser sustentado, irremediablemente, por el exclusivo sentir del individuo. Y quizás por esto mismo, ciertas dudas respecto al listado de derechos humanos suscrito por Naciones Unidas a través de la Declaración Universal de Derechos Humanos, así como respecto a su fuerza efectiva y aplicación práctica, siguen siendo notables. La misma, al tratarse de un acuerdo materializado, dicho sea de paso, en un momento histórico de gran agitación y poderosos miedos, por muy elaborada que resultase ser y por muy sobre-

${ }^{28}$ Denomino "acuerdo implícito» en este contexto a una decisión final que, en principio, es tomada por unos pocos en base a algún tipo de delegación de una mayoría, delegación que termina abarcando, a su vez, contenidos muy amplios y generales que escapan al control individual del sujeto que delega. 
saliente que fuera la personalidad de aquellos que parecían haber sido elegidos para representar, justo en esa precisa ocasión, a los seres humanos del pasado, presente y futuro, no deja de adolecer, como mínimo, de muchos de los problemas que acompañan a las teorías intersubjetivas del significado. Dificultades que, por otra parte, son connaturales al individuo y a su forma de conceptualizar ya que, al igual que ninguna de las modernas teorías del lenguaje terminó siendo la panacea respecto a nuestras posibilidades de acceso al conocimiento objetivo, tampoco la Declaración Universal de los Derechos Humanos, más allá de sus aciertos, ha resultado ser la panacea en relación al conocimiento y práctica de dichos derechos.

Ciertamente, no es de esperar un elixir mágico que espante alegremente todos nuestros fantasmas de aquí en adelante. Ante los mismos, sólo caben propuestas que aligeren la carga existencial destapando nuevas esencias. Sin embargo, es posible que el misterio haya sido visto, al menos por algunas de estas teorías, más bien como un enemigo al que hay que eliminar que como un necesario y grato compañero de viaje. En este sentido Bernard D'Espagnat, ilustre científico, viene afirmando desde hace un tiempo la importancia del misterio como uno de los elementos constitutivos del ser, de tal forma que la ciencia no puede pretender, tal y como en ocasiones parece querer hacer, su supresión ${ }^{29}$. De hecho, precisamente por ser un elemento constitutivo del ser es por lo que hemos podido trazar, en grandes momentos de inspiración, sendas que parecen acercarnos en buena medida a esta ininteligible realidad. Y, en cuanto a estas sendas se refiere, el arte es sin duda una de las más relevantes ${ }^{30}$.

${ }^{29}$ D'Espagnat, Bernard, «Revista Geo Internacional», 2009, www.mundo-geo.es/ ciencia/los-limites-de-la-ciencia-donde-esta-la-verdad. D’Espagnat estima que la realidad última no puede ser descrita, siendo tan misteriosa que no somos capaces de conocerla ni de imaginarla. Aún así, el propio autor afirma que «la sensibilidad que despierta el arte puede facilitar a la mente humana la percepción de realidades más profundas».

${ }^{30}$ Con el ánimo de rebautizar esa extraña sensación que nos produce el misterio, personalmente prefiero mantener ligado el mismo al ámbito del propio conocimiento. Es por ello por lo que particularmente lo «conceptúo» como «conocimiento diferido». Al respecto nos pueden servir, a modo de metáfora, los experimentos neurológicos que se están realizando en la actualidad y que, poco a poco, nos van aproximando a la gran nebulosa de nuestro cerebro. En esta línea, parece ser que en dicho órgano, antes de que llevemos a efecto determinadas acciones que consideramos conscientes, ya se ha tomado la elección previamente. Es decir, cuando surge la visualización de nuestra decisión, ya «se ha optado» por la misma, previamente, sin que nosotros «lo sepamos». Teniendo en cuenta esto, ¿podría ser que la razón del misterio estuviese en nosotros mismos y aún no hubiese sido visualizada? 


\section{DE LA DESVINCULACIÓN ENTRE TEORÍA Y PRÁCTICA. POR UNA LÓGICA ARTÍSTICA}

Resultaría demasiado simple considerar que nuestra capacidad para percibir realidades más profundas, como por ejemplo aquella que concierne a los derechos humanos, pase únicamente por el desarrollo de un cierto tipo de lógica y argumentación. Si esto es así, la teoría de los derechos humanos, teoría que hace depender casi toda su conceptualización de un concreto uso y análisis del lenguaje, se verá irremediablemente mermada pues este proceder tiene ciertos límites que también los juristas han de tener presentes. Sin embargo, cabe la posibilidad de modular estas limitaciones. Un ejemplo relativo al idioma es, como ya hemos visto, la poesía.

Karl Vossler, en un trabajo que lleva por título "Los límites de la sociología lingüística» ${ }^{31}$, sugiere ciertas ideas que nos pueden ayudar a descifrar la importancia del talento artístico incluso en el campo semántico: "Evidentemente, la distinción entre poesía y prosa es algo exterior, es decir, formal, y quien la toma externamente y [...] califica de poesía las formas de hablar de apariencia simétrica y de prosa las de apariencia asimétrica, ciertamente no anda muy descaminado [...] Así es que mi estudio tocaría a su fin si no tuviéramos el convencimiento de que tras la relación externa sin duda ha de esconderse otra interna [...] A la prosa, en este sentido interior, pertenecen por consiguiente aquellas formas de hablar que, aunque puedan aparecer exteriormente como poesía o como prosa o como mezcla de ambas, han resultado de una intención, temple psíquico, humos o inspiración esencialmente prosaicos [...] La prosa, cuanto más llana, legítima y prosaica sea, tanto más resueltamente rehúye todo lo que sea sentir, temple emocional e inspiración y tanto más busca lo lógico [...] Pero la cuestión es si consigue realmente la prosa, es decir, el prosista, libertarse del estado sentimental y del lirismo uniéndose con el Logos a vida y muerte. Con otras palabras: si la forma interior de la prosa es lógica. De la naturaleza lógica del lenguaje, especialmente del lenguaje prosaico, han estado de hecho bastante convencidos los filósofos y gramáticos de la Antigüedad, del Medievo y hasta del Iluminismo [...] Y no llegó a lograr validez una nueva concepción hasta el año 1885, con el libro del discípulo de Humboldt, Heinrich Steinthal, Gramática Lógica y Psicología, sus principios y relaciones mutuas. Steinthal demuestra por menudo, clara y victoriosamente, que el pensar idiomático es una cosa por completo distinta del lógico, que las palabras no son idénticas a los conceptos, ni las frases a los juicios, sino a lo más, en el mejor de los casos, representaciones de

${ }^{31}$ VossLer, Karl, «Filosofía del lenguaje», Buenos Aires, Editorial Losada, 2008.

(C) UNED. Revista de Derecho UNED, núm. 14, 2014 
conceptos y juicios. Con algunas limitaciones las ideas de Steinthal son aceptadas por la lingüistica actual. Apenas hay ya un lingüista que se atreva a contar lisa y llanamente con la naturaleza lógica del lenguaje» ${ }^{32}$.

Es así que, tras las palabras parece existir algo que escapa a la lógica y, con ello, a la definición racional de la cosas. Visto así, ¿qué puede hallarse tras cualquier definición habitual de los derechos humanos? Por desgracia, tras este tipo de descripciones muy usualmente parece quedar, tan sólo, una concatenación de términos semánticamente relacionados entre sí y que suelen vincularse a una concreta manera de hacer racionalista. En relación a esto, Vossler continúa afirmando que «no es sostenible la opinión intelectualista de que la inteligencia, la razón, los conceptos, abstracciones y generalizaciones sean adquisiciones más altas y tardías, frente al hablar infantil del hombre primitivo [...] el pensar lógico ya alumbra en las primeras y más simples manifestaciones idiomáticas del hombre primitivo o del niño [...] Al penetrar el pensamiento lógico en el idiomático, éste se hace tan poco lógico y aquél tan poco idiomático como el rayo solar se pueda quedar mojado en el agua o como el agua se pueda volver luz. Es cierto que se producen reflejos, pero no mezclas ${ }^{33}$

Y en esta explicación, Vossler hurga en la herida, pues tras un primitivo «ay» existe, como mínimo, tanta razón como la que puede cobijar todo un compendio en prosa sobre el perpetuo drama humano, o quizás algo aún más mágico, como es la fusión entera del habla y el acto, una exteriorización de la que participa todo el ser. Pero la extrema intelectualización del lenguaje tiende a separar ambas realidades, y es por esto por lo que Vossler llega a diferenciar la expresión que el idioma genera del hecho que tiene lugar. A esta lógica posterior al lenguaje, la cual otorga validez a un término para que pueda reflejar una acción, el autor alemán la define como «conciencia lógica», resaltando con ello la función simbólica del lenguaje que «es en su origen, $y$ hoy mismo, esencialmente antropomórfica $»^{34}$, para concluir afirmando que la palabra es una cosa y el suceso o acción otra, interrelacionándose ambos, palabra y suceso, a través del lenguaje.

Esta separación entre hecho y palabra afecta negativamente al conocimiento más elemental pero, sobre todo, a aquel que indaga en la obtención de una mayor y más certera determinación de los conceptos. Por ello, Vossler se plantea la superación de la simple interre-

\footnotetext{
${ }^{32}$ Ibídem, págs. 231-233. El subrayado es mío.

${ }^{33}$ Ibídem, pág. 233.

${ }^{34}$ Ibídem, pág. 234.
} 
lación entre palabra y acto en aras de «ese momento ideal del arte en que [...] logos y lenguaje, hasta donde es posible lograr su unión, tienen que hacerse actividades simultáneas. En lo demás, cada una de entrambas actividades puede seguir su propio camino como mejor sepa; pero cada vez que algo lógicamente significativo, por ejemplo un conocimiento científico, tiene que llegar a representación idiomática, se impone al filósofo más grande la misma necesidad del momento que al niño balbuciente: su abstracta especulación, sus conceptos más altos y más puros tienen que bajar de su altura y dejarse envolver en los pañales idiomáticos que están preparados para ellos precisamente en ese momento histórico [...] Todo pensar científico está envasado en alguna lengua determinada, y se precisa un trabajo penoso -precisamente un trabajo científico-, para liberarlo de ella, y la liberación no es posible más que por su trasiego a otras formas de expresión y a otras lenguas [...] alli donde el concepto esté expuesto idiomáticamente, alli hay un lado opaco. Para defender el logos con algún éxito contra tales ensombrecimientos debidos al lenguaje, se necesita la unión de la abstracción crítica y del talento artístico, de la maestría científica y de la idiomática, que en verdad en pocas cabezas de da. ${ }^{35}$

Semejante talento artístico es necesario, como bien dice Vossler, para liberar el lado opaco de los conceptos expuestos idiomáticamente. Conceptos generados para el aquí y el ahora y, consecuentemente, limitados por el tiempo. Porque «acaso la brevedad de la vida y la urgencia por llevar a conclusión nuestras pobres ideas sean culpables de muchos estrechamientos. Pero el eterno e incorregible culpable sigue siendo siempre el lenguaje humano" ${ }^{36}$. Un culpable que también fue reconocido desde otro mundo muy distinto, lejos del ámbito científico y al amparo de la poesía, por Juan Ramón Jiménez. Una culpa en la que acabaron coincidiendo el poeta que parecía buscar la razón prosaica (Jiménez) y el prosista que parecía buscar la razón poética (Vossler).

La ciencia exige prosa, pero ansía poesía, es decir, talento artístico, pues "poesía y prosa se atraen recíprocamente de tal manera que aunque se alejan a las veces la una de la otra [...] luego vuelven siempre a fortalecerse mutuamente en nuevas confluencias y nuevos trenzados. El poeta puro, el sólo-poeta, en cuya sangre falta el hierro filosófico y prosaico, se enteca, languidece y decae en el lirismo [...] y los científicos puros se secan y aplastan en un intelectualismo desespiritualizado,

35 Ibídem, págs. 235-237.

${ }^{36}$ Ibídem, pág. 238. No sé si Juan Ramón Jiménez era conocedor del pensamiento de Vossler pero, ¡cuánta semejanza esconden sus reflexiones! Recordamos una vez más: "Acaso la mentira, la duda de este mundo / está en la pobre lengua nuestra... ». 
como les ha pasado a tantos materialistas, naturalistas y positivistas exactos que no necesito nombrar en particular. El historiador de la literatura los reconoce en seguida, más que en anda, en que escriben una prosa abyecta.» ${ }^{37}$.

Los costes que puede provocar la desvinculación entre prosa y poesía son extrapolables a cualquier faceta de nuestra existencia. La «desespiritualización» de la palabra convirtiéndola en algo inerte, en teoría ajena a la vida y a la práctica, es uno de los posibles efectos de esta separación. Y puede que esta falta de sincronía sea el mayor riesgo que asola a los derechos humanos, una relajación y despreocupación respecto a su valor y a sus posibilidades de configuración que nos distancia de los mismos en nuestra cotidianidad. Unas posibilidades que, en esencia, son de nuestra responsabilidad y que, afectando a todos los ámbitos de nuestra vida, en verdad, no exigen de un gran listado, pues su fundamento quizás sea más unitario de lo que podamos sospechar.

Equilibrio y armonía, fundamento de arte y de vida ante el cual nuestra sensibilidad se descubre, quedando afectada ante la más pequeña oscilación. Justamente esta sensibilidad, ciñéndonos al ámbito de los derechos humanos, parece alertarnos de un cierto desequilibrio entre la ingente labor teórica llevada a cabo (especialmente durante las últimas décadas) y los efectos prácticos que se han derivado de la misma. Ciertamente, las expectativas son grandes y, por eso mismo, es sano que las decepciones sean lo suficientemente intensas, teniendo siempre muy en cuenta la dimensión del desafío. Los derechos humanos nos obligan a rastrear un desbordante saber que, en su capacidad de expansión, rebosa constantemente nuestros límites, ya sea desde el conocimiento más concreto ceñido a la norma positiva, ya sea desde el conocimiento más abstracto ceñido al concepto. Un saber que, aún siendo un todo, hemos de experimentar en nuestro reducido cuerpo gracias a vivencias y emociones que encajen armónicamente en nuestras vidas.

Las reflexiones en torno a las divergencias entre teoría y praxis son un tema recurrente dentro de la filosofía, pues si decepción nos causaba el desajuste entre vida y obra de un artista, no menos contrariedad produce este mismo fenómeno aplicado a los filósofos, tal y como afirma Alexander Nehamas en su libro "El arte de vivir» ${ }^{38}$. A este respecto el autor afirma lo siguiente: «el hecho de que la vida de los fi-

${ }^{37}$ Ibídem, pág. 247.

${ }^{38}$ Nehamas, Alexander, "El arte de vivir. Reflexiones socráticas de Platón a Foucault», Valencia, Pre-Textos, 2005. 
lósofos no refleje sus convicciones provoca un sentimiento de desilusión y confusión» ${ }^{39}$. Aseveración, por cierto, aplicable a todos y cada uno de nosotros y que, sin duda alguna, es un punto de conexión entre filósofos (y resto de mortales) y artistas: su obra como reflejo de su propia vida.

Semejante desazón, dentro de un cierto orden, es un sentimiento muy sano porque «la teoría y la práctica, el discurso y la vida, se afectan entre sí; los hombres se hacen filósofos porque pueden y quieren ser el mejor tipo de ser humano y vivir de la mejor manera posible. Hay una influencia directa ente lo que uno cree y cómo se vive» ${ }^{40}$. Y es que una radical separación entre teoría y praxis puede conducirnos a formas de estar como la de «algunos filósofos [que] quieren encontrar respuestas a preguntas generales e importantes, incluyendo preguntas acerca de la ética y la naturaleza del bien vivir, sin creer que sus respuestas tengan mucho que ver con el tipo de persona que ellos terminan siendo». Una manera de estar que se distancia de la de «otros [que] creen que estas ideas, cuando se organizan de forma correcta y tienen un real impacto en la vida cotidiana, terminan creando una vida buena». Siendo así que, para los primeros (el caso de la teoría pura) «lo único que importa [...] es si las respuestas a las preguntas son correctas o no", mientras que para los segundos (el caso de la teoría que afecta a la vida) «la verdad de nuestras ideas todavía tiene una importancia central, pero lo que también importa es el tipo de persona, el tipo de ser, que se logra construir como resultado de su aceptación ${ }^{41}$.

Extrapolando estas reflexiones al ámbito de los derechos humanos, podemos considerar lo sugerente que resulta el desafío de tratar de encontrar la verdad en relación al significado y contenido de este tipo de derechos, pero también podríamos preguntarnos si no es aún más sugerente meditar respecto a la huella que han de dejar en nuestro ser, y en nuestro estar, nuestras ideas en torno a ellos.

Palabra y vida deberían estar estrechamente unidas y, en muchas ocasiones, por pretender encontrar la tan ansiada verdad, tristemente terminamos eliminando de la palabra gran parte de su vitalidad y, por lo tanto, la reducimos a un funcional elemento lógico que, cuando ha de enfrentarse a la «razón» de la "sinrazón», muestra inevitablemente unas carencias que intentamos solapar a costa de un uso banal de la misma. Insistimos, la realidad cuenta con matices inabarcables por el idioma, realidades que no se pueden nombrar, impresiones de verda-

\footnotetext{
${ }^{39}$ Ibídem, pág. 12.

40 Ibídem.

${ }^{41}$ Ibídem, pág. 13.
} 
des que nos desconciertan y nos llevan a un mundo difícilmente definible pues, como diría Juan Ramón Jiménez, «no sé con qué decirlo, / porque aún no está hecha / mi palabra» ${ }^{42}$.

Pero que nuestra palabra no esté hecha no significa que estas realidades no existan, ni tampoco que no seamos capaces de experimentarlas y comunicarlas. Abrirse camino respecto a lo desconocido exige un trabajo verdaderamente artístico, un trabajo que podemos llevar a cabo si somos capaces de desarrollar nuestra sensibilidad. A lo largo de este camino puede que la palabra siga sin manifestarse, pero nuestro ser estará abriendo nuevas fuentes de comunicación, un ser que, dicho sea de paso, es mucho más extenso que el habla.

\section{ARTE Y DERECHOS HUMANOS: UNA RELACIÓN SUGERIDA}

Una de las más hermosas particularidades del arte es su capacidad para mostrar, a través de un determinado continente o forma, un contenido o fondo que va más allá de la representación corpórea. Dicho contenido nos aproxima a un tipo de verdad inmaterial, o aspiración ideal, que planea sobre nuestras vidas pero que tiende a evaporarse en nuestro día a día. Con la ilusión de evitar este distanciamiento, el ser humano siente la necesidad de tomar contacto con semejante esencia en busca de paz y armonía personal. En este sentido, los derechos humanos son una especie de herramienta práctica, un instrumento funcional creado por el individuo con la intención de no perder el contacto con la idealidad. Indudablemente, si algo ha demostrado el ser humano es una enorme capacidad técnica en relación al conocimiento del entorno y la adaptación al mismo pero, respecto al conocimiento de su propia alma y adaptación a ella, ¿el avance ha sido tan notorio ${ }^{43}$

La comprensión «intelectual» de las cosas no siempre va acompañada de una comprensión «emocional». El cuerpo y el sentimiento no siempre siguen al intelecto y, en relación al desciframiento de los misterios que se esconden tras el paradigma de los derechos humanos, es fundamental que todo nuestro ser esté dispuesto a conocer. Camille Pissarro creía necesario tener un poco de armonía para poder expresar las ideas, circunstancia de la cual deducía que era bueno experi-

42 JimÉnEZ, Juan Ramón, «Lírica de una Atlántida», óp. cit., pág. 25.

${ }^{43}$ A lo largo del artículo he usado en varias ocasiones el término «alma»y, en este momento, me gustaría apuntar que en dicho uso hay un deseo consciente de que el lector adapte esta expresión a su particular visión de lo más profundo de su ser, de sus miedos, deseos, anhelos, temores y esperanzas. 
mentar sensaciones para tener ideas. Esta conclusión parece ser una apuesta por un conocimiento integral y si Pissarro estaba en lo cierto, cuanta más armonía sintamos, más posibilidades tendremos de poder expresar determinadas ideas. Y digo «sintamos» pues Pissarro habla directamente de sensaciones. De este modo, la armonía con dichas sensaciones nos dará la posibilidad de vislumbrar el concepto y, puede que lo más importante, de poder comunicarlo.

La reflexión sobre las sensaciones que conducen al ser humano a idear los derechos humanos nos obligan a viajar atrás en el tiempo y enlazarlo con nuestro presente. Si recordamos, Karl Vossler negaba la posibilidad de que fenómenos como la inteligencia, la razón, los conceptos, las abstracciones o las generalizaciones fuesen adquisiciones más altas y tardías frente a un hablar infantil del hombre primitivo ${ }^{44}$. $Y$ es que puede que nuestro hablar fuera infantil en aquellos tiempos no tan lejanos, pero nuestra capacidad para sentir era ya muy compleja, al igual que nuestra capacidad para conceptualizar. Unas sensaciones y unos conceptos que, si profundizamos en ellos, nos pueden llevar a mirar con otros ojos los derechos humanos. Una mirada en la que, por cierto, el arte tiene mucho que decir.

Considerar que nuestros sentimientos respecto a los derechos humanos son mucho más avanzados y mejores que los de nuestros parientes más primitivos podría ser un grave error. Puede que ellos no contasen con la palabra, pero contaban con una sensibilidad y una razón suficiente que hacía de su mundo interior un mundo ya intenso y abundante, un mundo en donde las emociones empezaban a dar cuenta del ser y del propio universo, un mundo que, en esencia, no ha cambiado tanto. Una vida marcada ya por un especial talento sensitivo. Un balbuciente ser humano que empezaba a pronunciar sus primeras grandes palabras a través del arte.

Justamente esta prehistoria artística nos aporta una de las más incipientes pruebas del sentido de la armonía en el ser humano, un sentido que le permite empezar a fundamentar el mundo observado e, incluso, el mundo que no puede observarse, es decir, el mundo de las ideas, con la esperanza de poder encontrar el vínculo fundamental entre el universo y su propia existencia. Es así que, desde la observación, el sujeto empieza a tomar conciencia de la propia simetría de su cuerpo $^{45}$, decantándose por formas y líneas que le resultarán particularmente relevantes y que utilizará para ir modelando, poco a poco,

\footnotetext{
${ }^{44}$ VossLer, Karl, óp. cit., 233.

${ }^{45}$ BAYER, Raymond, "Historia de la estética», Madrid, Fondo de Cultura Económica de España, 1986, pág. 10.
} 
aquello que, en principio, permanece fuera del campo de observación más diáfano escondiendo el secreto de la esencia. De esta forma, la prehistoria no es sólo un viaje al pasado, también es un viaje al futuro gracias a la manifestación de los vínculos que ligan al ser humano a lo largo del tiempo y que, a cada paso que damos, nos hacen vislumbrar lo que hemos sido y lo que seremos.

$\mathrm{Al}$ igual que nosotros, el hombre prehistórico llega a presentir una verdad más allá del mundo observable y, lanzándose a la búsqueda de la misma, comienza a manipular la realidad consciente dando lugar a la fuerza expresiva del arte ${ }^{46}$. Son los primeros arrebatos enmarcados en una larga lucha del ser humano por intentar hacer consciente el inconsciente, por llegar a fundir realidad material y realidad inmaterial, por tratar de alumbrar lo más oscuro de su ser. Ciertamente un alumbramiento... Pues allí, da igual el lugar y la hora, tuvo lugar la primera manifestación de humanidad. Una manifestación eterna, ya que toda manifestación humana supera los límites temporales reuniéndonos a todos en torno a ella. Allí, en ese tiempo remoto, «quizá la primera vez que un miembro de las hordas primigenias, uno de aquellos hombres que aún no tenían lenguaje, al ver muerto a su compañero de especie, a su pareja, a su hijo, a su padre, con fiereza animal y desconsuelo amanecientemente humano gritó sin fin contra el silencioso universo» ${ }^{47}$. Y quizás ese grito fue la conformación del primer derecho humano. Un sincero e inmenso mensaje de «consuelo ante el infinito desconsuelo humano ${ }^{48}$. Un grito que, por ejemplo, recupera una y otra vez el quejío flamenco para, a través del arte, hacernos presente el pasado y el futuro.

El cante, gran declaración humana que recuerda y hace memoria, sin odio y con calma, para intentar sanar las heridas sufridas a lo largo del camino. Una celebración, pues el ser humano no sólo ha celebrado «el sol, las cosechas, los nacimientos, la iniciación, las bodas, las victorias: y siempre las celebrara. [También] el ser siempre ha llorado la oscuridad, las muertes, la desunión, la vejez, las derrotas y las injusticias: y las llorará siempre» ${ }^{49}$. Y lo ha hecho también a modo de celebración, es decir, tratando de reconciliarse con su esencia, con temple y solemnidad. Esa esencia que pretenden evocar los derechos humanos y a la que arriba el flamenco. Ese arte en el que "hay siglos de dolor, [y] hay más desdicha de la que puede rodear con sus brazos desaforados $»^{50}$. Desdicha y, precisamente por esto, un especial sentido

\footnotetext{
${ }^{46}$ Ibídem, pág. 11.

${ }^{47}$ Grande, Félix, óp. cit., pág. 31.

${ }^{48}$ Ibídem.

${ }^{49}$ Ibídem, pág. 34.

${ }^{50}$ Ibídem, pág. 50.
} 
de la libertad, pues se trata, tal y como afirmaría Caballero Bonald, de «un grito sin rebeldía, una resignada protesta, algo así como la liberación de una queja personal sin destinatario » ${ }^{51}$.

Sin destinatario concreto. Rebosante de libertad. Esta es su grandeza. Ni tan siquiera, en su recogimiento, el flamenco es una queja personal contra alguien. Y por ello este paciente arte, lentamente, va extiendo sus alas abarcando nuestra memoria familiar y nuestras emociones compartidas, amparando todo dolor humano ${ }^{52}$. Pues cuando un cantaor se dispone a cantar, no canta simplemente su pena, canta la pena de sus hermanos, de su familia, de sus ancestros y de todo aquel que pueda verse reflejado en ella ${ }^{53}$. Este es el verdadero sentido de la hermandad, y es verdadero porque es fundamentalmente "sentido", y es fundamentalmente sentido porque traspasa la forma para llegar a un fondo que, desde esta particular mirada artística, es el que da sentido a la forma, y no al revés, lo que nos permite expandir nuestras posibilidades de conocimiento. Un fondo que libera a la forma y que Plotino visualizó en los siguientes términos: "Hay en la naturaleza una razón, que es el modelo de la belleza perteneciente a los cuerpos; pero hay en el alma una razón más bella aún, de la que deriva la belleza que se encuentra en la naturaleza ${ }^{54}$. Pero, ¿cómo acceder a ella?

Puede que este acceso consista, al menos primariamente, en esa peculiar mirada que el arte ha tratado de potenciar en un constante esfuerzo por materializar la belleza en todo su apogeo. Un esfuerzo que nos acerca a un particular modo de conceptualizar, al estilo pitagórico, en el que «todo lo que se encuentra en el ámbito de la mesura, en la armonía, está dotado de razón, de inteligencia y de vida; y todo lo que es, es vivo, piensa y siente ${ }^{55}$. Todo lo que es... Ecos de una verdad

51 Ibidem, pág. 51.

52 Ibídem, págs. 87-93.

53 "La tragedia casi siempre es plural. Pero el cante se expresa en primera persona. [...] desde el suceso trágico del cante se proyecta el drama colectivo. Pero, en lo más hondo de su exacta turbulencia expresiva, el cante no alude al futuro de un pueblo, sino a su drama; no alude a la rebelión de un padecimiento, sino a su intensidad; es rico en rabia, pero no en organizado coraje [...] El cante flamenco no es propiamente una música popular. Es un dolor popular-y racial-que se expresa utilizando las vidas de unos cuantos agonistas desaforados de tensión. Algo muy radical pugna por ser dicho y se dice a través de ellos. Se dice desde lo colectivo. Pero se dice personalmente [...] Si no relacionamos a la música -ese esfuerzo de la emoción por ser expresión sonora y de la expresión sonora por constituirse en mapa del ser-con la penuria y con la cárcel, la brutalidad y la represión, el hambre y el miedo, la amenaza y la prepotencia, la resistencia y el secreto, no obtendremos el cante flamenco». Ibidem, págs. 123 y 130.

54 BAYER, Raymond, óp. cit., pág. 80.

55 Ibídem, págs. 29-31. 
latente que reúne en torno a ella a cada individuo. Un individuo que, desde sus incapacidades, miedos, inseguridades y complejos intenta capturar la integridad de la vida, la relación fundamental entre el instante y lo eterno, entre lo particular y lo plural, entre la parte y el todo. Un juego armónico que trata de concentrar lo máximo posible lo incorpóreo en la forma, de evocar la sustancia en lo corpóreo.

Sin duda alguna, han sido muchos los talentos que han intentado plasmar este sentimiento esencial de plenitud pero, si hay que destacar un periodo histórico al respecto, tanto por su especial creatividad, como por su energía y vigor, hemos de referirnos necesariamente al Renacimiento. Alberti, Bramente, Brunelleschi, Botticelli, Piero della Francesca, Lippi, Bellini, Leonardo, Miguel Ángel, Rafael... Una constelación de artistas dispuestos a marcar unas pautas agraciadas en pos de la razón del hombre/universo, cultivando para ello un especial sentido de la belleza. Tantos y tantos ejemplos que, forzosamente, debemos acotar nuestra perspectiva. Pero bastará con acercarnos sutilmente al paradigma de un hombre celestial, contradicción muy apropiada para referirnos a Rafael Sanzio, un artista que con su obra dará sobradas muestras del sentido estético y humanista de este tiempo, así como de su singular concepción de la libertad, la dignidad y la justicia. Antes, recordemos brevemente nuestras primeras reflexiones sobre el lenguaje.

Planteábamos al inicio del presente artículo una serie de problemas respecto a las posibilidades lingüísticas ofrecidas por el idioma para la aprehensión, por parte de nuestra mente y de nuestro cuerpo, de la razón contenida en los derechos humanos, una razón de volumen inabarcable que nos conecta con un primario sentimiento que, sólo después, intenta ser conceptualizado. Este orden, previo sentimiento y posterior conceptualización, es connatural al ser humano, pues en esencia nuestro sentir es menos limitado que nuestro conceptuar, por muy elaborado que este último pueda llegar a estar. Precisamente esta capacidad para conceptualizar, en su desarrollo, puede acabar por alterar dicho orden llegando a priorizar el concepto sobre el sentimiento lo que, antes o después, provoca un grave distanciamiento entre teoría y acto. En todo caso, sentimiento y concepto no son dos compartimentos estancos. Cuanto más desarrollada esté nuestra capacidad para sentir, más capacidad para conceptualizar tendremos y, de un modo u otro, encontraremos la vía más adecuada para comunicar dicha conceptualización. Sin embargo, recorrer el camino inverso puede dificultar, a la larga, mucho más las cosas pues el concepto correrá serios riesgos de terminar distanciándose de nuestra propia realidad vital, es decir, de nosotros mismos. Concep- 
tualizar en base a realidades no sentidas nos conduce al ser autómata. Priorizar el sentimiento de nuevas realidades para proceder después a su conceptualización nos conduce a la libertad. Este posicionamiento puede ser, en un primer momento, poco satisfactorio desde un punto de vista lógico pero es posible que, amparados en la gracia de ciertos dones, como es el caso de nuestras facultades artísticas, podamos vislumbrar una referencia más certera de la verdad. Una referencia que, aún siendo sentida por lo más profundo de nuestro ser, puede que no termine nunca de ser comprendida por nuestro intelecto.

Para poder sacar a la luz y divulgar este sentimiento, el ser humano recurre a la simbología rompiendo los esquemas de ciertos límites racionales. La palabra llega a estos límites cuando el referente no es claro y unívoco, es decir, cuando el referente no está asociado directamente a la palabra. Es en este momento cuando se nos exige el concepto, herramienta desde la cual se pretende dar cierto cuerpo a lo que permanece vago, etéreo y abstracto. A este respecto, en el arte simbólico más primario encontramos los primeros intentos por adecuar la forma a la idea ${ }^{56}$. Aún así, en esos tiempos la idea se antojaba aún demasiado vasta, "infinita como el espíritu y las concepciones humanas», no pudiendo ser "abarcada en la imagen sensible e imperfecta que se le tiene que dar» ${ }^{57}$. Sin embargo, el punto de inflexión llegará con el arte clásico, momento en el cual el artista, ciertamente ayudado por el desarrollo técnico, se centrará en tratar de alcanzar todo aquello que el arte preclásico quiso proponer pero no pudo culminar, es decir, la fusión de los distintos elementos, la sucesión armoniosa entre lo inmóvil y lo móvil, el perfeccionamiento, en definitiva, de la composición, núcleo de «todas las estéticas clásicas y la más clásica de las definiciones de lo bello: la unidad en la variedad ${ }^{58}$.

De entre todos aquellos que consiguieron culminar esta hermosa propuesta sobresalen figuras como la de Rafael, genio cuya conceptualización de lo bello corona la idea que nutre todo el arte renacentista. Una idea que, de hecho, llegó a materializar pues, en palabras de Goethe, "Rafael ha hecho siempre lo que los demás soñaban hacer ${ }^{59}$. Pero, ¿cómo pudo conseguirlo?

Para dar respuesta a esta pregunta tendríamos que gozar de la capacidad de poder observar directamente el alma de Rafael pero, como indudablemente esto no es posible, hemos de adentrarnos en su

${ }^{56}$ Ibídem, pág. 103.

${ }^{57}$ Ibídem.

${ }^{58}$ Ibídem, pág. 104.

${ }^{59}$ De Martino, P., óp. cit., Vol. 7, pág. 35. 
misterio a través de las señas que él mismo nos proporcionó a través de su arte. Con ello estableceremos, aún sin querer, una relación fundamental entre sus pinturas y su alma. En este sentido, de la obra del maestro de Urbino se desprende una pureza sin igual basada en un constante juego de correspondencias, en un conjunto de líneas y curvas que se entrelazan suave y rítmicamente, en un equilibrio y orden compositivo superior que atribuye a su arte una paz, armonía y gracia tal que, al ser contemplado, sumerge al espectador en un estado tan ilusorio, placentero y espiritual que, podríamos decir, le lleva a entrever el paroxismo de la dignidad ${ }^{60}$.

Todo en Rafael sugiere este mundo ideal al que aspira el individuo y en donde los límites entre lo divino y lo humano se pierden. Rafael, gracias a su inusual capacidad, consiguió realizar uno de los sueños del mismísimo Leonardo, «la imposible representación de un universo, cuya armonía deriva de los movimientos de una serie de mundos, perceptibles cada uno de ellos en la ilimitada vastedad del conjunto" ${ }^{61}$. Y por esto, por ser su arte un ejemplo de síntesis único e ideal, contenido infinito que consigue ser reflejado en un espacio y tiempo limitados, con las obras de Rafael (junto a su alma) nos adentramos en un especial tipo de universo: "Todo lo que el Humanismo había deseado, todos los ideales que habia intuido [...] toda esta suma de aspiraciones cristalizaban en realidades gracias a Rafael. Pasada la Edad Media [...] en el momento en que el hombre cobraba conciencia de sí mismo y que su grandeza y dignidad no sólo eran descubiertas, sino fortalecidas por el descubrimiento de los clásicos, en que, llevado por su impulso juvenil, el hombre podía ya imaginar verse sumergido en un ambiente de pura y humana sabiduría, en este preciso momento un artista creaba ese ambiente en el que todo era sabio y mesurado y en el que el ideal se convertía en poética realidad [...] No importaba que las condiciones de vida fuesen desastrosas [...] Por un instante, la Humanidad, encarnada en unas pocas figuras de excepción, había tenido una visión humanamente paradisíaca de sí mismo y Rafael fijaba esa visión ${ }^{62}$.

${ }^{60}$ «Nosotros somos seres inquietos, angustiados, escépticos o creyentes, hombres, en suma, que sufren y se agitan, y sólo podemos comprender en la esfera del arte a quien nos muestre nuestra imagen o un reflejo de ella. Pero, en Rafael no hay sufrimiento ni inquietud; en Rafael no puede encontrar su reflejo nuestra alma. ¿Se comprende ahora, la dificultad de comunicarse con él? Y sin embargo, si es verdad que a veces, en el curso de nuestra vida y aunque haya sido por breves instantes, [...] nos hemos sentido con el alma liberada de trabas materiales aspirando a vivir en una atmósfera de pura armonía, entonces también nos será posible identificarnos con Rafael, porque él -y sólo él entre los modernos-es quien ha conseguido darnos una representación de este mundo mágico». Ibídem.

${ }^{61}$ Ibídem, pág. 43.

${ }^{62}$ Ibídem, pág. 36. 
Efectivamente, a pesar de su grandeza el de Urbino no fue un oasis en el desierto. Por suerte, el mundo que Rafael nos hizo presente fue un mundo al que asombrosamente también se pudo acceder de muy diversos modos y, en particular, a través de una de las más sinceras comunicaciones con la idea, dada su abstracción: el lenguaje de los hermosos sonidos y los contemplativos silencios.

Si Beethoven llegó a afirmar que la música es una revelación más alta que ninguna filosofía, aquellos que compartimos la idea del genial compositor y pianista estaremos de acuerdo en concluir que, al respecto, mucho le debemos a Johann Sebastian Bach, «sinónimo de orden, de pureza, de claridad y de simplicidad elevada a una potencia espiritual inigualada» ${ }^{63}$. Una música que nos hace partícipes del enorme privilegio de intuir una eternidad y aproximarnos a la esencia, gracias a una inmensa sensación de libertad y paz. Bach fue un milagro, puede que uno más de tantos y tantos ante los cuales permanecemos ciegos pero que, en el caso de este genio, tuvo la gran oportunidad de sobresalir y expandirse. Una vida intensa y dolorosa que halló alivio en la música. Un sufrimiento acogido en cada nota y calmado a lo largo de los sucesivos compases. Un consuelo que, ante una realidad desconcertante, también nos ampara y protege a todos nosotros.

El ser humano, al vivir en una constante paradoja a la que es incapaz de dar solución, al no poder generar lazos de unión entre diversos polos que son sentidos como opuestos, se adentra repetidamente en intensas crisis que le sumen en la desesperanza. La obra de Rafael, al igual que la obra de Bach, son intentos por romper este esquema vital, una propuesta en la que confiar y que nos invita a atisbar una realidad en la que creer, pues su ofrecimiento cuenta con especial valía. Arte que nos encamina a un fin que muy bien podría ser el fin de los derechos humanos.

No obstante, si a pesar de todas estas razones terminamos por considerar que los ejemplos dados son complejas metáforas que nos separan de una concreta vinculación, explícita y clara de los derechos humanos con el arte, entonces vayamos al terreno de lo manifiesto. Allí puede que nos encontremos con "Peter Grimes», de Benjamin Britten, o con su «War Requiem, Op. 66». Probablemente también tropecemos, casi sin querer, «entre las brumas del dolor y la muerte, en este viaje por el mal del que es capaz el hombre [...]», con Leos Janácek $\mathrm{y}$ "Desde la casa de los muertos», mostrándonos "el leve y esperanzador brillo de la bondad humana [...]» y construyendo «un canto a la

${ }^{63}$ Dufource, Norbert, «La Música», Tomo II, Libro V, Capítulo II, Barcelona, 1988, pág. 318. 
libertad $\aleph^{64}$. Quizás redescubramos el barroco español o terminemos dándonos de bruces con los primeros atisbos del modernismo en la pintura gracias a Francisco de Goya.

$\mathrm{Y}$ entonces, tras estos impactantes encuentros, cada uno de nosotros en nuestra vorágine de trabajo, estudiosos de los derechos humanos o no, allá en nuestro tumultuoso y fugaz vivir y en nuestra realidad llena de preocupaciones personales, puede que sintamos, aún por un fugaz momento, un tropiezo nuevo y sorprendente con el contenido infinito de los derechos humanos.

\section{CONCLUSIONES}

La lucha intelectual por dar sentido y contenido a los derechos humanos se fundamenta, al menos en principio, en una razón lógica: si se consigue demostrar discursivamente su relevancia, más posibilidades habrá de que los individuos los reconozcan y, consecuentemente, los lleven a la práctica. Sin embargo, tras el discurso relacionado con los derechos humanos, un discurso que acompaña al ser humano desde siempre aunque de diferentes formas, parece aguardar un perenne halo de frustración dada la incapacidad del sujeto por eliminar un sufrimiento que, por si fuera poco, en muchas ocasiones se ceba con el más débil. Por supuesto, este triste sentimiento no ha de obviar los logros obtenidos al respecto, éxitos que en muchas ocasiones se han basado en un importante esfuerzo intelectual y argumentativo de muchos individuos pero que, por desgracia, no ha conseguido extender sus efectos todo lo que ellos hubiesen deseado. Y es que el sentimiento, por mucho que se contraponga al mismo una razón perfectamente lógica desde un punto de vista intelectual, suele ser mucho más poderoso.

El arte, en relación a esto, deja impreso su mensaje no sólo en el intelecto, sino también en el cuerpo, y es esta conexión entre razón y sensación, por muy sutil que pueda ser, lo que sitúa a esta disciplina en un particular lugar dentro del mundo del conocimiento y, por qué no decirlo, en relación a una posible conceptualización y materialización de los derechos humanos. Semejante particularidad tiene, a mi entender, una gran importancia. Desde finales del siglo XVIII se viene trabajando muy intensamente en una correcta definición de los derechos humanos, labor que resulta indudablemente necesaria a ciertos

${ }^{64}$ Teatro Real, «Desde la casa de los muertos», Temporada 2005-2006, Madrid, Publicaciones del Teatro Real, 2005, pág. 98. 
niveles y para ciertos propósitos. Aún así, a nivel general, y a pesar del cúmulo de definiciones dadas, lo más efectivo parece seguir siendo relatar e identificar a los derechos humanos por lo que no son más que por lo que son. Es decir, en verdad el individuo (incluido el docto en la materia) suele saber más de la indignidad que de la dignidad, de la injusticia que de la justicia, de las cadenas que de la libertad... O al menos esto es lo que siente. Y semejante circunstancia es muy reveladora.

Cuando hablábamos del sentimiento de frustración que rodea al discurso relativo a los derechos humanos, apelábamos al sentimiento porque éste nos da una información que la gran mayoría de definiciones «en positivo» obvian. Sabemos más sobre qué es lo que no son los derechos humanos que sobre qué es lo que son porque, en verdad, sabemos más del sentimiento que provoca en nosotros la indignidad, la injusticia o la falta de libertad que la dignidad, la justicia y la libertad. La teoría de los derechos humanos ha intentado encontrar este tipo de definición «en positivo», revoloteando muy a menudo sobre ciertos tópicos y centrándose principalmente en un tipo de comprensión intelectual más que "corporal», cuando no contraponiendo ambos tipos de conocimiento ${ }^{65}$. Comprensión que, por cierto, si ya es difícil de alcanzar cuando se parte de una idea que, quizás, no ha sido suficientemente sentida y vivida, entonces se torna prácticamente en un imposible cuando se intenta transmitir a otros sin tener en cuenta su particular sensibilidad.

Spinoza dedicó parte de su «Ética» a tratar de dilucidar la vía que conduce a la felicidad, para lo cual, consecuentemente, se propuso fijar previamente el concepto de la misma. Ante esta circunstancia, Miguel de Unamuno llegó a exclamar: «iEl concepto! ;El concepto y no el sentimiento!»66. Este es nuestro principal reclamo respecto a los derechos humanos, una llamada que en un primer momento podría parecer circunstancial pero que, en nuestra opinión, es fundamental. Hemos de empezar a sentir la dignidad, acercarnos a ella, vivirla en positivo. ¿Recordamos un momento de nuestras vidas en el que este sentimiento nos haya inundado? ¿Podemos rememorar los instantes

${ }^{65}$ Cuando hablo de comprensión intelectual me refiero al paradigma de la razón ilustrada, sobre todo de la razón lógica, método imperante, con sus luces y sus sombras, desde el siglo XVII pero que, en no pocas ocasiones, derivó en un absolutismo intelectual en pos de desechar, paradójicamente, una parte importante del antiguo iluminismo místico.

${ }^{66}$ De Unamuno, Miguel, «Del sentimiento trágico de la vida», Barcelona, Ediciones Folio, 2002, pág. 63. 
en los cuales hemos sentido la libertad o, por desgracia, nuestro encuentro con la misma siempre se ha ceñido a su carencia?

Se podría pensar que sabiendo lo que una cosa no es, resulta fácil vislumbrar lo que es. Y puede que dicho modo de reflexionar sea válido a nivel lógico, mas no parece serlo a nivel emocional. Nietzsche pareció apuntar una idea sugerente en este sentido: "Hay más razón en tu cuerpo que en tu razón. Y también aquello que llamas tu sabiduría; quién sabe para qué tiene tu cuerpo necesidad de esa sabiduría» ${ }^{67}$. Pues nuestra razón podrá pugnar desesperadamente por encontrar un conocimiento válido referente a los derechos humanos pero, mientras nuestro cuerpo y nuestros sentidos, en su máxima extensión, no nos acompañen en esta labor, no negamos ciertos éxitos, pero las probabilidades de desilusión en relación a nuestros fines y logros seguirán siendo demasiado altas.

Seguramente, los caminos para alcanzar este sentimiento sean infinitos pero, dentro de nuestro limitado mundo, el arte nos ofrece una posibilidad esperanzadora. Gracias al mismo, intelecto y cuerpo se funden, nuestra razón llama a nuestra sensibilidad y el ritmo de nuestro conocimiento se mueve al ritmo de nuestro corazón. El gran Rafael no sólo captó, y nos hizo captar, los secretos de la armonía a nivel físico, material y matemático. Fue más allá. Trató de percibir, y hacernos percibir, la armonía a nivel espiritual, nos guió con el propósito de hacernos sentir este particular fenómeno. ¡Sentir la armonía! ¿Hay un sentimiento que pueda acercarnos más, y «en positivo», a la libertad, a la dignidad o a la justicia? Empaparse de este arte es empaparse de estos sentimientos, y estos sentimientos nos abren las puertas de un conocimiento que va más allá de palabras y definiciones.

Se trata de un camino semejante al que pareció querer transitar, y hacernos transitar, Johann Sebastian Bach. Un camino de pureza, de equilibrio, de majestuosidad y de misericordia que discurre eterno y sin límites. Si conseguimos dejarnos llevar por estos caminos, todos orientados a un mismo fin, quizás descubramos un tipo de comprensión más vigorosa y segura sobre los derechos humanos que aquella que nos tratan de ofrecer numerosos textos jurídicos. Quizás podamos vivir un significado que puede estar pacientemente esperándonos, entre bellos fragmentos, en su única misa, en alguna de sus «Pasiones», en "El arte de la Fuga» o, quién sabe, en alguna de las «Variaciones Goldberg».

${ }^{67}$ Nietzsche, Friedrich, «Fragmentos póstumos», Madrid, Abada, 2004, pág. 97. 
En todo caso, y una vez apuntado el tema, nuestro propósito más humilde estaría ampliamente satisfecho si algún paciente lector se siente impulsado a aproximarse al arte y, con ello, a los derechos humanos, con una nueva perspectiva. 
